
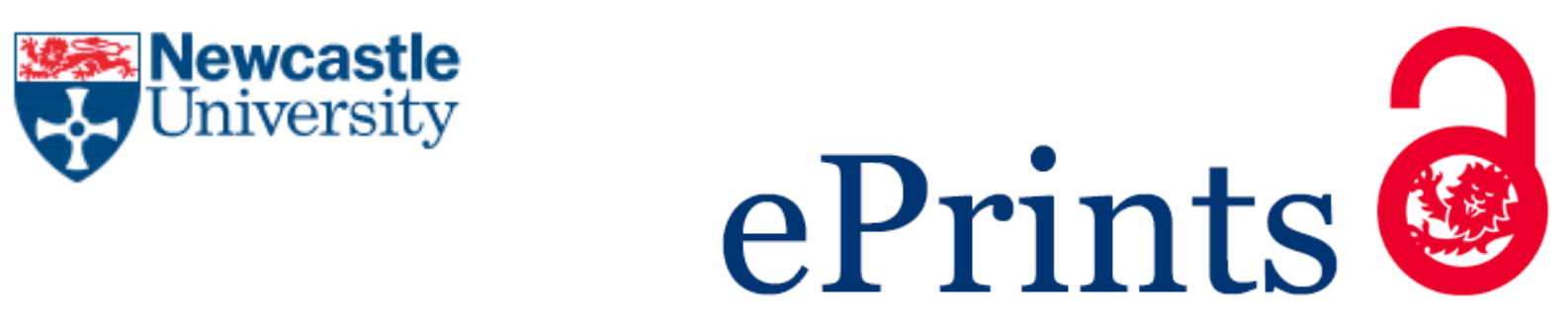

Chen X, Yu X, Lu Y, Huang R, Liu Z, Huang Y, Roskilly AP. Study of different cooling structures on the thermal status of an Internal Combustion Engine. Applied Thermal Engineering 2017, 116, 419-432.

\title{
Copyright:
}

(C) Elsevier 2017. This manuscript version is made available under the CC-BY-NC-ND 4.0 license

DOI link to article:

10.1016/i.applthermaleng.2017.01.037

Date deposited:

$27 / 06 / 2017$

Embargo release date:

30 January 2018

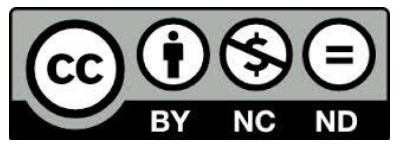

This work is licensed under a

Creative Commons Attribution-NonCommercial-NoDerivatives 4.0 International licence 


\section{Study of Different Cooling Structures on the Thermal Status of an Internal Combustion Engine}

Xiaoqiang Chen ${ }^{a}$, Xiaoli Yuª, Yiji Lu ${ }^{b}$, Rui Huang ${ }^{a}$, Zhentao Liư ${ }^{a}$ Yuqi Huanga,*, Anthony Paul Roskilly

${ }^{a}$ Department of Energy Engineering, Zhejiang University, Hangzhou, 310027, China

${ }^{b}$ Sir Joseph Swan Centre for Energy Research, Newcastle University, Newcastle NE1 7RU, UK

Highlights:

- A 3D single cylinder engine model was developed for thermal status analysis

- Conventional, top-bottom and split cooling structures were investigated

- The optimal cooling structure was identified and studied

\section{Abstract:}

Different cooling structures for cylinder head and block and the corresponding thermal status, thermal dissipation and frictional power dissipation were investigated in this study.

In a conventional engine cooling configuration, the coolant flow travels from the block to the head, leading to the coolant temperature of the head being higher than that of block. Furthermore, the over-cooling *Corresponding author: Tel:+ 86 (0) 571-87951874

E-mail address: huangyuqi@zju.edu.cn (Y. Huang) 
problem in the block will occur because the cooling system is designed for the cooling requirements of the cylinder head without considering the cooling load of the block.

This paper developed a 3D single cylinder model to analyse the influence of coolant flow direction and split structure cooling for the head and block. The analysis indicated that the top-bottom flow cooling structure can effectively reduce the cylinder head thermal load and slightly increase the temperature of the cylinder liner. The combined split and top-bottom cooling structure is proven as the optimal solution with the advantages of lower thermal and frictional power dissipation compared with that of the conventional cooling structure.

Key words: Different cooling structures, Temperature status, 3D single cylinder engine model, Thermal and frictional power dissipation

\section{Introduction}

The growing concerns on energy crisis and environmental problems are raising the research attentions on energy saving and emission reduction technologies for Internal Combustion Engine (ICE) to improve the overall energy efficiency. Diesel engine convers less than $40 \%$ of the fuel energy into the effective power from the crankshaft and wasted the remaining fuel energy through the exhaust gas system and cooling system [1-5]. The heated components in ICE such as cylinder head requires to be used under high thermal stress conditions, which will increase the potential of components damage with the increase of combustion intensity [6, 7]. The development of alternative and advanced cooling system with precisely controllable strategies is quite important to replace the conventional engine cooling system. 
In conventional engine cooling system, the engine rotational speed determines the coolant pump speed and speed of radiator fan, which means the engine cooling load cannot be adjusted according to the thermal load under different working conditions. Some researchers conducted the investigation on intelligent cooling systems to achieve precisely controlling cooling strategies using smart controlling electrical components to replace the conventional components such as wax thermostat valve, mechanical water pump and radiator fan [8-14]. By adopting smart cooling controlling strategies engine warm-up time and $\mathrm{CO}_{2}$ emissions can be effectively reduced [8].

In engine operational conditions, the thermal load of the cylinder head is higher than that of the block, but the coolant flow can only travel from the block to the head through the upper hole in traditional cooling system [5], which will lead to temperature of the cylinder head higher than that of the block. On the other hand, the coolant flow rate for ICE is designed based on the thermal limitations of the cylinder head, which requires a larger cooling intensity than that of block part, which will cause over cooling problem on the block. Therefore, advanced cooling system is desirable to avoid the over cooling problem on cylinder liner and potentially reduce the temperature field of the cylinder head. Considering the various cooling requirements of heated components, multiple cooling circuits can effectively control the temperature conditions in separately cooling circuits. Cipollone et al. [15]proposed a novel engine cooling sytem with two circuits including an HT (high temperature) circuit for the engine, EGR cooler, oil cooler, $1^{\text {st }}$ stage inter-cooler and a LT (low temperature) circuit for the $2^{\text {nd }}$ stage inter-cooler and A/C condenser. The two circuits cooling system can optimize the cooling demands of different heated components in ICE $[15,16]$. Moreover, the two circuits cooling system can reduce the overall fuel consumption and simplify the front end model of the engine compartment $[15,16]$. Kang et al. [17] studied on an engine smart cooling system with double loop coolant structure, which indicated the smart cooling system can effectively control the temperature of the 
cylinder head and block resulting in the reduction of fuel consumption and engine warm up time. Cipollone et al. studied two split coolant structure schemes for head and block cooling [18]. In these schemes, coolant flows from the cylinder head to the block and the valve between the water jackets of the cylinder head and the block was controlled to adjust the coolant flux, which can control the temperature of the cylinder head lower than that of the block with proper flow repartition [18]. For industrial application, a double circuit cooling system was launched in a Ford gasoline engine to independently control the component temperature by thermostat[19]. Results indicated the block temperature can be increased more quickly under a split cooling structure, and the friction between the liner and piston is reduced in cold running conditions [19].

However, the previously conducted researches all studied the mean temperature of the cylinder head and block at different cooling structures with 1D simulation model, which cannot represent the coolant flow conditions under different coolant flow directions or different coolant flux of the head and block cooling system. Furthermore, the temperature distribution and thermal stress of the heated components, thermal dissipation from the coolant and frictional power dissipation of the water jacket require to be further studied to understand the effects of different cooling structures. A 3D engine simulation model is therefore necessary to investigate the effect of different cooling structures on the thermal status of the heated components, thermal dissipation and frictional power dissipation.

In this study, a 3D single cylinder engine model was built to study the temperature and thermal stress field of the cylinder head and liner. Moreover, the frictional power and thermal dissipation for different cooling structures under engine rated condition were analysed and compared in the following sections. Finally, the 
optimal cooling structure was further studied under various engine power outputs, which can be used as important references to conduct further study on the development of advanced cooling organization strategies for Internal Combustion Engine. 


\section{Nomenclature}

$1 T \quad$ temperature

$2 \lambda \quad$ thermal conductivity

$3 h \quad$ convective heat transfer coefficient

$4 \theta \quad$ rotating angle

$5 k \quad$ turbulence kinetic energy

$6 \quad \varepsilon \quad$ turbulent dissipation rate

$\begin{array}{lll}7 & c & \text { thermal capacity of solid }\end{array}$

$8 \boldsymbol{t}$ time

$9 \rho \quad$ density

$10 \mu \quad$ dynamic viscosity

$11 v \quad$ kinematic viscosity

$12 F \quad$ body force

$13 \phi \quad$ thermal dissipation function

$14 G_{k} \quad$ turbulence kinetic energy induced by

15 velocity difference

$16 G_{b} \quad$ turbulence kinetic energy induced by

17 buoyancy

34

Subscript

$35 w \quad$ wall

$36 g$ gas

$37 c \quad$ coolant

$38 k \quad$ turbulence kinetic energy equation

$39 \varepsilon \quad$ turbulent dissipation rate equation

$40 m$

$41 r$

mean value

r location
$42 \beta \quad$ dimensionless distance

$43 f \quad$ frictional

$44 \quad T \quad$ total

$45 \quad$ cylinder head

$46 \quad q \quad$ mass flow rate

$47 v \quad$ volume flow rate 


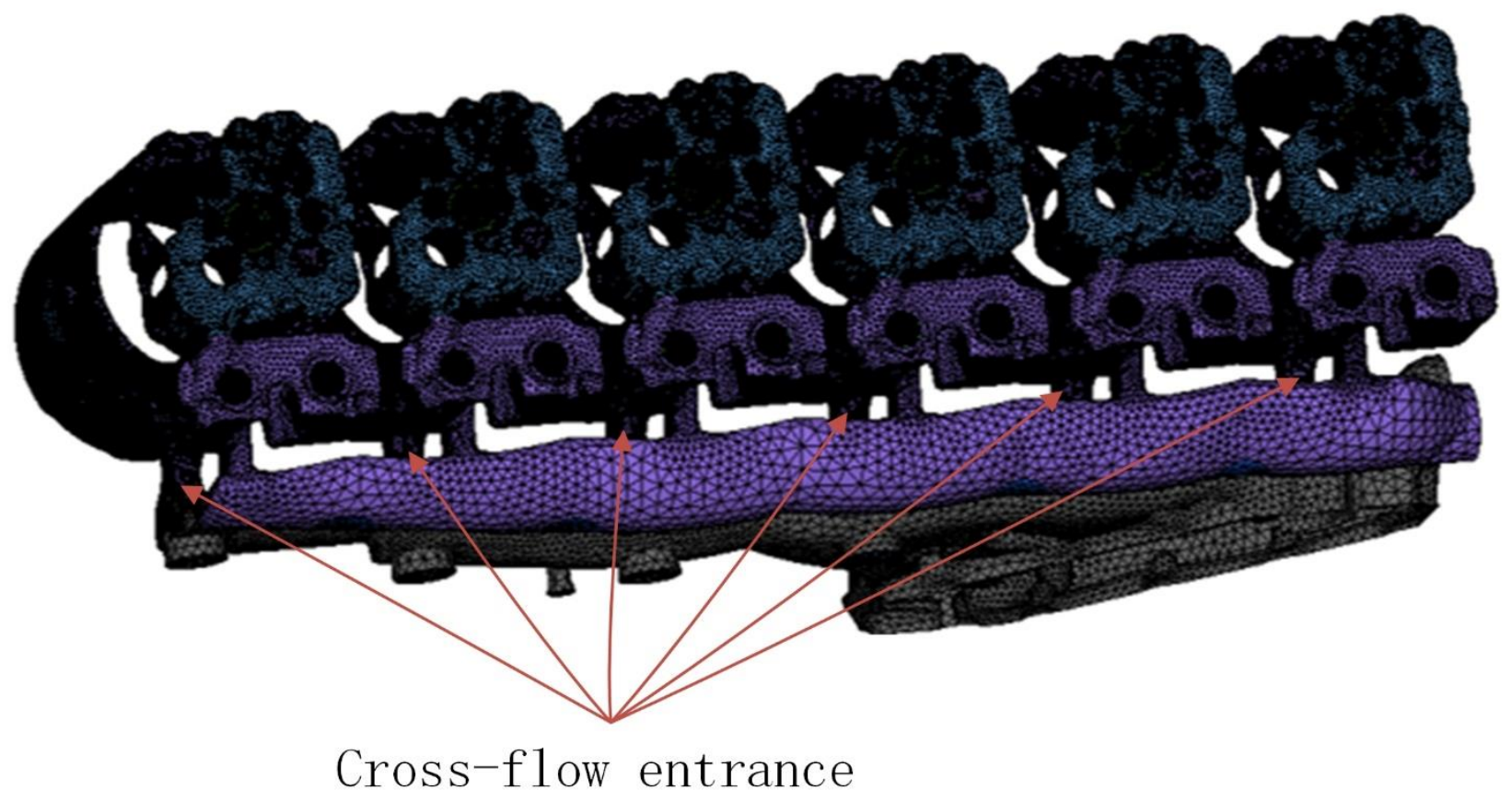

Fig. 1. Coolant mesh of six-cylinder engine model

A six cylinder diesel fuelled engine was selected to be investigated in this study. The selected engine contains six

51 separate cylinder heads with independent and identical cooling gallery structure. Because the coolant flow circuits in 52 this engine are designed as cross-flow entrance as indicated in Figure 1, the six-cylinder engine can be simplified as a

53 single cylinder engine to investigate the effects of different cooling organization strategies on the thermal conditions,

54 frictional power and thermal dissipation of the heated components. 

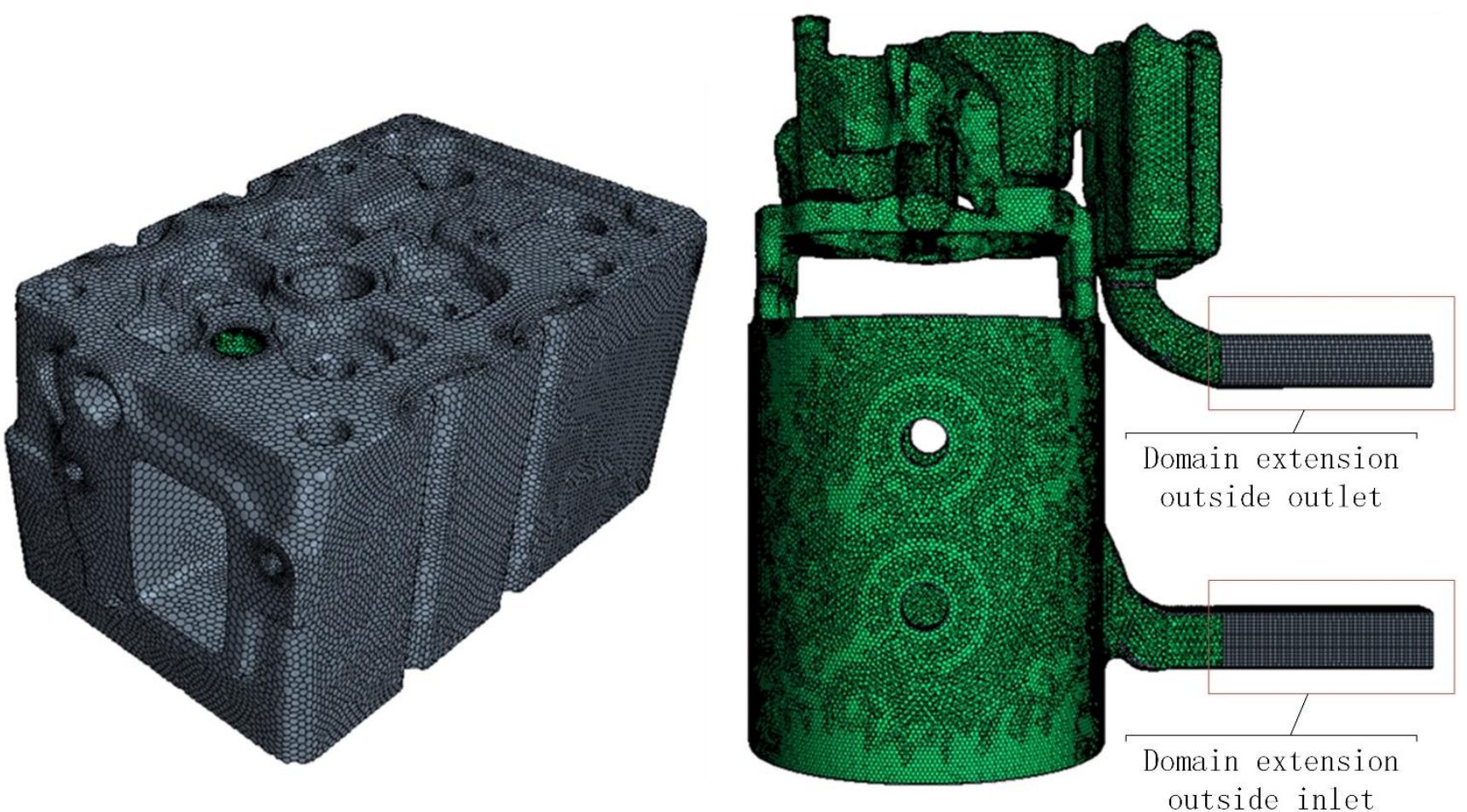

Fig. 2. Mesh of the single cylinder engine model

56 The single cylinder engine model mainly includes the engine head, cylinder liner, engine cylinder block, engine seat

57 and the cooling gallery, which has the similar structure and function of the six-cylinder engine as mentioned

58 previously. The Mesh of the single cylinder engine model was generated by the software STAR-CCM+, which was

59 produced by Computational Dynamics-Analysis \& Design Application Company Ltd for CFD analysis[20]. The grid

60 quantities of the single cylinder model can be found in Table 1. In order to achieve the fully developed inlet and

61 outlet boundary conditions[21], the computational domain was extended as illustrated in the Figure 2.

Table 1

Grid quantities of the different regions

\begin{tabular}{|c|c|}
\hline Region & Grid quantity \\
\hline Cylinder head & 175250 \\
\hline Liner & 348543 \\
\hline
\end{tabular}


Seat

Fluid

636362

64

\section{Numerical Simulation Model}

\subsection{Heat transfer equations}

67 The solid region of the model adopts the steady heat conduction equation as described in Equation (1).

$$
\frac{\lambda}{\rho c}\left(\frac{\partial^{2} T}{\partial x^{2}}+\frac{\partial^{2} T}{\partial y^{2}}+\frac{\partial^{2} T}{\partial z^{2}}\right)=0
$$

The fluid-solid interconnection to describe the interface between the fluid and solid region is defined based on the Fourier heat equation and the convective heat transfer control equation as illustrated in Equation (2).

$$
-\left.\lambda\left(\frac{\partial T}{\partial n}\right)_{w}\right|_{s o l i d}=\left.\mathrm{h}\left(T_{w}-T_{c}\right)\right|_{\text {fluid }}
$$

\subsection{Description of the Fluid Model}

73 The coolant can be recognized as incompressible fluid [22, 23], which can be described as the following continuity,

74 momentum and energy equations.

$$
\left.\begin{array}{c}
\nabla U=0 \\
\nabla(\rho u \vec{u})=F_{x}-\frac{\partial p}{\partial x}+\frac{\partial \tau_{x x}}{\partial x}+\frac{\partial \tau_{x y}}{\partial y}+\frac{\partial \tau_{z x}}{\partial z} \\
\nabla(\rho v \vec{u})=F_{y}-\frac{\partial p}{\partial x}+\frac{\partial \tau_{x y}}{\partial x}+\frac{\partial \tau_{y y}}{\partial y}+\frac{\partial \tau_{y z}}{\partial z} \\
\nabla(\rho w \vec{u})=F_{z}-\frac{\partial p}{\partial x}+\frac{\partial \tau_{x z}}{\partial x}+\frac{\partial \tau_{y z}}{\partial y}+\frac{\partial \tau_{z z}}{\partial z}
\end{array}\right\}
$$

The Reynolds-averaged Navier-Stokes equations and k-epsilon equation are adopted in this study for the numerical calculation. 


$$
\frac{\partial}{\partial t}(\rho k)+\frac{\partial}{\partial x_{i}}\left(\rho k u_{i}\right)=\frac{\partial}{\partial x_{i}}\left[\left(\mu+\frac{\mu_{t}}{\sigma_{k}}\right) \frac{\partial k}{\partial x_{i}}\right]+G_{k}+G_{b}-\rho \varepsilon
$$

$$
\frac{\partial}{\partial t}(\rho \varepsilon)+\frac{\partial}{\partial x_{i}}\left(\rho \varepsilon u_{i}\right)=\frac{\partial}{\partial x_{i}}\left[\left(\mu+\frac{\mu_{t}}{\sigma_{\varepsilon}}\right) \frac{\partial \varepsilon}{\partial x}\right]+C_{1 \varepsilon} \frac{\varepsilon}{k}\left(G_{k}+C_{3 \varepsilon} G_{b}\right)-C_{2 \varepsilon} \rho \frac{\varepsilon^{2}}{k}
$$

81 The wall function method is used to describe the boundary layer, where turbulent is not suitable to be used in near

82 wall region and the Reynolds number is too small to use standard k-epsilon equation. In the wall function method,

$83 \mathrm{y}^{+}$is defined as dimensionless distance and $\mathrm{u}^{+}$is the dimensionless velocity. In this simulation model, the fluid field

84 is obtained by SIMPLE algorithm and the second order upwind discretization method is used to iterate the governing 85 equation. As the convergence criteria, the residual value of energy equation is set smaller than $10^{-6}$ and the residual 86 value of the other equations is set smaller than $10^{-3}$.

$$
\begin{gathered}
\mathrm{y}^{+}=\frac{\Delta \mathrm{y} \rho u_{w}}{\mu}=\frac{\Delta \mathrm{y}}{v}\left(\frac{\tau_{w}}{\rho}\right)^{1 / 2} \\
u^{+}=\frac{u}{u_{w}} \quad \begin{cases}\text { When } \mathrm{y}^{+}<11.63 & u^{+}=y^{+} \\
\text {When } \mathrm{y}^{+} \geq 11.63 & u^{+}=\frac{1}{k} \ln \left(E y^{+}\right)\end{cases}
\end{gathered}
$$




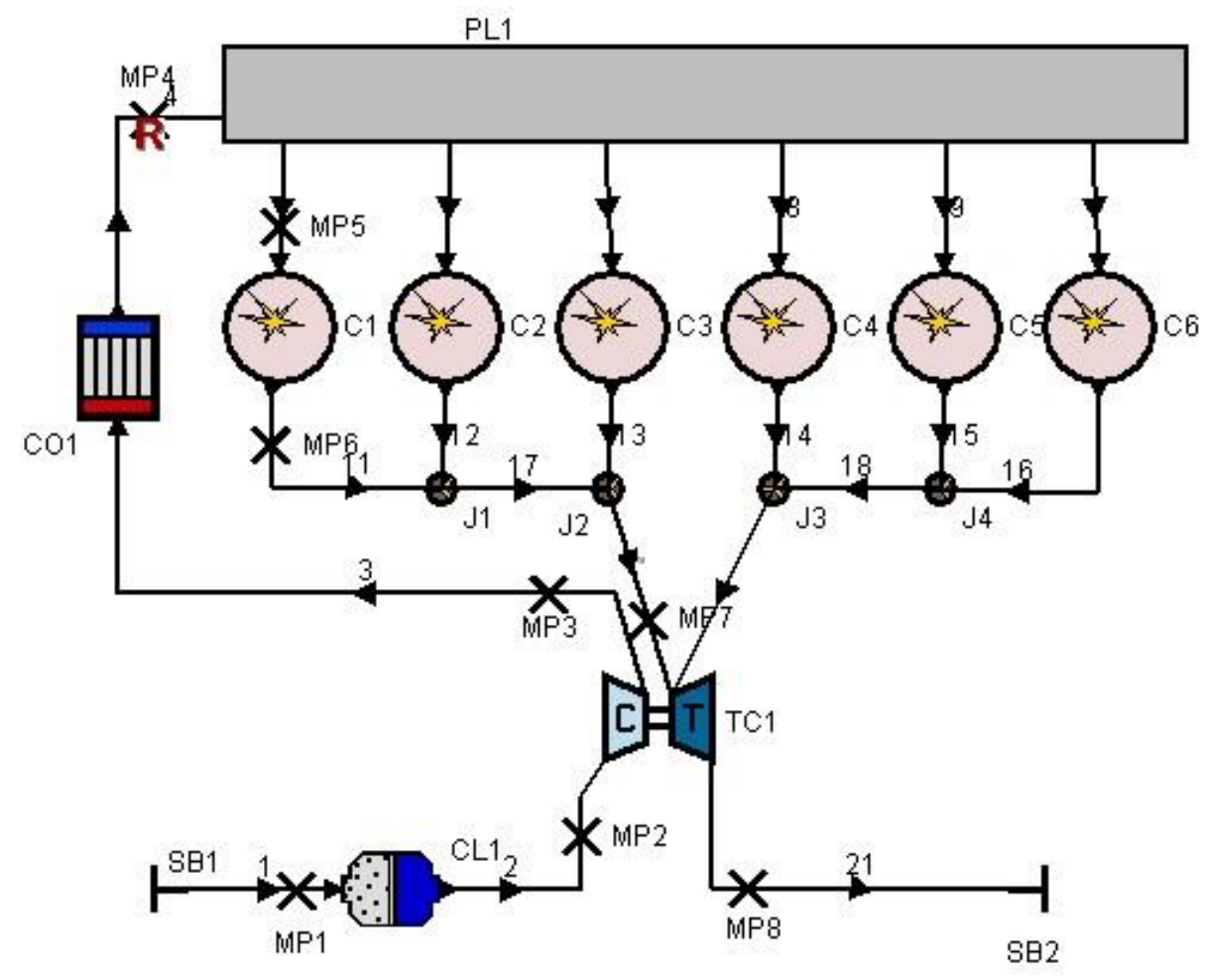

Fig. 3. 1D simulation for cylinder internal thermal boundary conditions

90 The specific power and the rotational speed of the selected six-cylinder engine rated condition is $29.16 \mathrm{~kW} / \mathrm{L}$ and

$911900 \mathrm{r} / \mathrm{min}$, respectively, which leads to the Indicated Mean Effective Pressure at $18.41 \mathrm{MPa}$. The thermal boundary

92 of the cylinder is using the third boundary condition, which obtains the values from a 1D combustion simulation

93 model. The 1D engine model is built by the software AVL Boost, which is designed for the simulation of Internal

94 combustion Engine [24]. The 1D engine simulation model built in AVL Boost is illustrated in Figure. 3 and the

95 simulation results were verified by the experiments in the engine rated condition. 


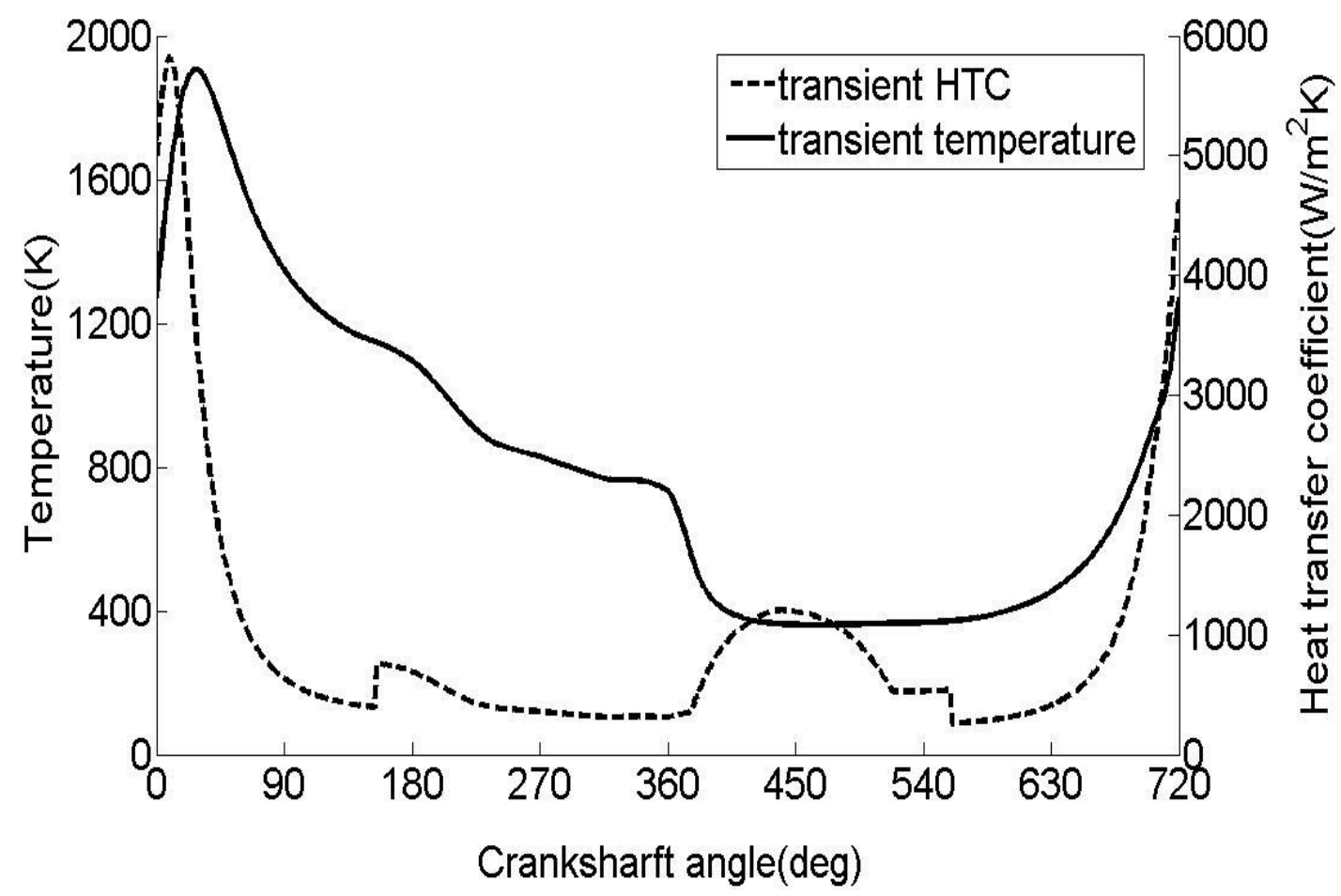

Fig. 4. Transient gas temperature and heat transfer coefficient in cylinder

97 The 1D simulation engine model was used to generate the transient burned gas temperature and heat transfer

98 coefficient (HTC) under different crankshaft angle as shown in Figure 4. The average gas temperature and HTC can

99 therefore be calculated by the following equations

$$
\begin{gathered}
T_{m}=\frac{\int_{0}^{4 \pi} h_{g} T_{g} d \theta}{\int_{0}^{4 \pi} h_{g} d \theta} \\
h_{m}=\frac{1}{4 \pi} \int_{0}^{4 \pi} h_{g} d \theta
\end{gathered}
$$




$$
h_{r}=h_{m}\left(-1.9401 x^{3}+1.1356 x^{2}+0.6834 x+0.602\right)
$$

Where $x=r / R$.

104 For the HTC distribution on the fire face of the cylinder liner [25], $\beta=\mathrm{H} / \mathrm{S}$ was defined as a dimensionless length in 105 the distribution functions,

$$
\begin{aligned}
& \text { If } 0 \leq \beta \leq 1, \\
& \left\{\begin{array}{l}
h_{\beta}=h_{m}\left(1+k_{1} \beta\right) e^{-\beta^{\frac{1}{3}}} \\
T_{\beta}=T_{m}\left(1+k_{2} \beta\right) e^{-\beta^{\frac{1}{2}}}
\end{array}\right. \\
& \qquad \begin{array}{l}
\beta>1 \\
\left\{\begin{array}{l}
h_{\beta}=h_{m}\left[1-k_{3}(\beta-1)\right]\left(1+k_{1}\right) e^{-1} \\
T_{\beta}=T_{m}\left[1-k_{3}(\beta-1)\right]\left(1+k_{2}\right) e^{-1}
\end{array}\right.
\end{array}
\end{aligned}
$$

Where $k_{1}=0.537(S / D)^{0.24}, k_{2}=1.45 k_{1}$ and $k_{3}=D / S$.

\subsubsection{Coolant boundary conditions}

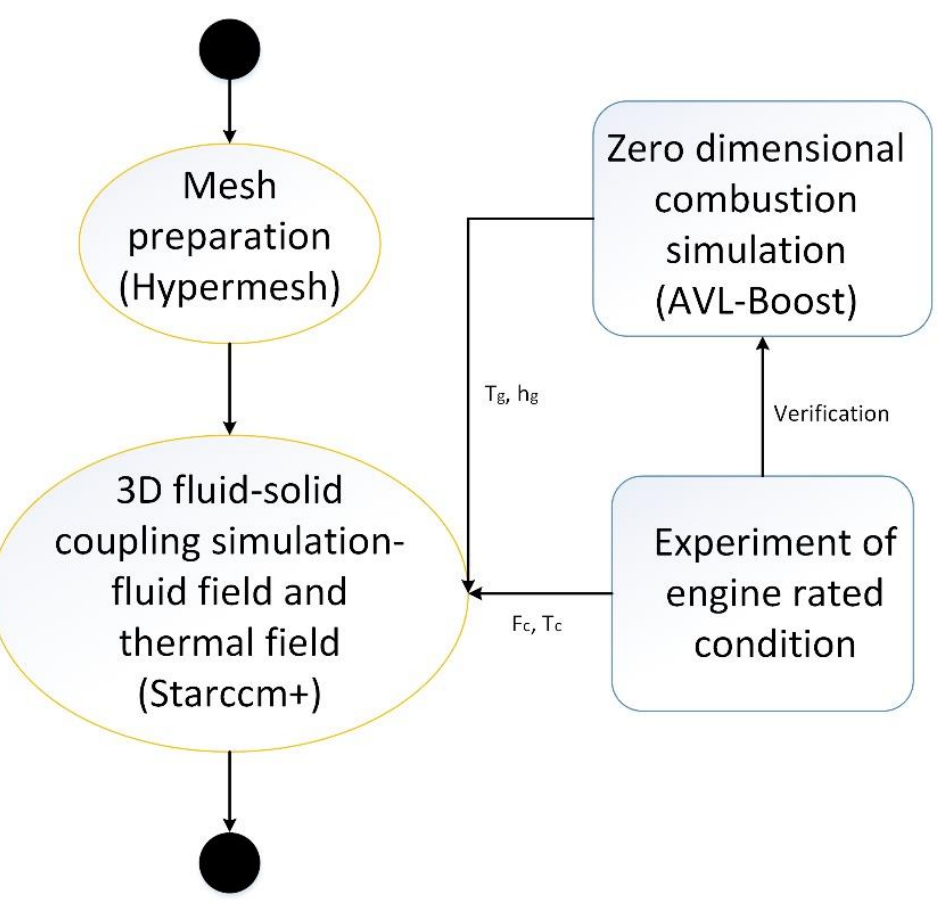

Fig. 5. Simulation procedure 
The boundary type of the inlet and outlet of the coolant is defined as Flux boundary and Flow split, respectively.

The coolant inlet flow rate and temperature are obtained from the engine thermal balance experiment of the six

cylinder engine. The integral procedure of the simulation model can therefore be established by using the defined

boundary conditions. The overall simulation process of the model can be illustrated as Figure 5 . The detailed

boundary conditions of the single cylinder engine model can be found in Table 2 .

Table 2

Boundary conditions of the single cylinder engine model

\begin{tabular}{|c|c|c|}
\hline Boundary & Boundary type & Value \\
\hline Inlet of coolant & Flux boundary & Flow rate $1.1 \mathrm{~kg} / \mathrm{s}$; Temperature $353 \mathrm{~K}$ \\
\hline Outlet of coolant & Flow split & Flow split \\
\hline \multirow[t]{2}{*}{ Wall of engine intake } & \multirow{2}{*}{ The third boundary condition } & Air charge temperature $337.7 \mathrm{~K}$; \\
\hline & & HTC $196.3 \mathrm{~W} /\left(\mathrm{m}^{2} \cdot \mathrm{K}\right)$ \\
\hline \multirow{2}{*}{ Wall of engine exhaust } & \multirow{2}{*}{ The third boundary condition } & Exhaust temperature $823 \mathrm{~K}$; \\
\hline & & $\mathrm{HTC} 668.5 \mathrm{~W} /\left(\mathrm{m}^{2} \cdot \mathrm{K}\right)$ \\
\hline \multirow{2}{*}{ Cylinder head oil gallery } & \multirow{2}{*}{ The third boundary condition } & Oil temperature $393 \mathrm{~K}$; \\
\hline & & $\mathrm{HTC} 150 \mathrm{~W} /\left(\mathrm{m}^{2} \cdot \mathrm{K}\right)$ \\
\hline \multirow{2}{*}{ Outside surface of block } & \multirow{2}{*}{ The third boundary condition } & Ambient temperature $298 \mathrm{~K}$; \\
\hline & & $\mathrm{HTC} 23 \mathrm{~W} /\left(\mathrm{m}^{2} \cdot \mathrm{K}\right)$ \\
\hline \multirow[t]{2}{*}{ Fire face of cylinder head } & \multirow[t]{2}{*}{ The third boundary condition } & Average burned gas temperature $1040.6 \mathrm{~K}$; \\
\hline & & Average HTC $933.5 \mathrm{~W} /\left(\mathrm{m}^{2} \cdot \mathrm{K}\right)$ \\
\hline \multirow{2}{*}{ Fire face of liner } & \multirow{2}{*}{ The third boundary condition } & Average burned gas temperature $1040.6 \mathrm{~K}$; \\
\hline & & Average HTC $933.5 \mathrm{~W} /\left(\mathrm{m}^{2} \cdot \mathrm{K}\right)$ \\
\hline
\end{tabular}


The coolant used in the simulation model is pure water. Therefore, the density, specific heat, thermal conductivity and dynamic viscosity of the coolant is $971 \mathrm{~kg} / \mathrm{m}^{3}, 4195 \mathrm{~J} /(\mathrm{kg} \cdot \mathrm{K}), 0.674 \mathrm{~W} /(\mathrm{m} \cdot \mathrm{K})$ and $0.0003551 \mathrm{~N} \cdot \mathrm{s} / \mathrm{m}^{2}$, respectively. The material of the cylinder head and block is $\mathrm{HT} 280$ with the thermal conductivity at $47.2 \mathrm{~W} /(\mathrm{m} \cdot \mathrm{K})$, when the ambient temperature is $293 \mathrm{~K}$.

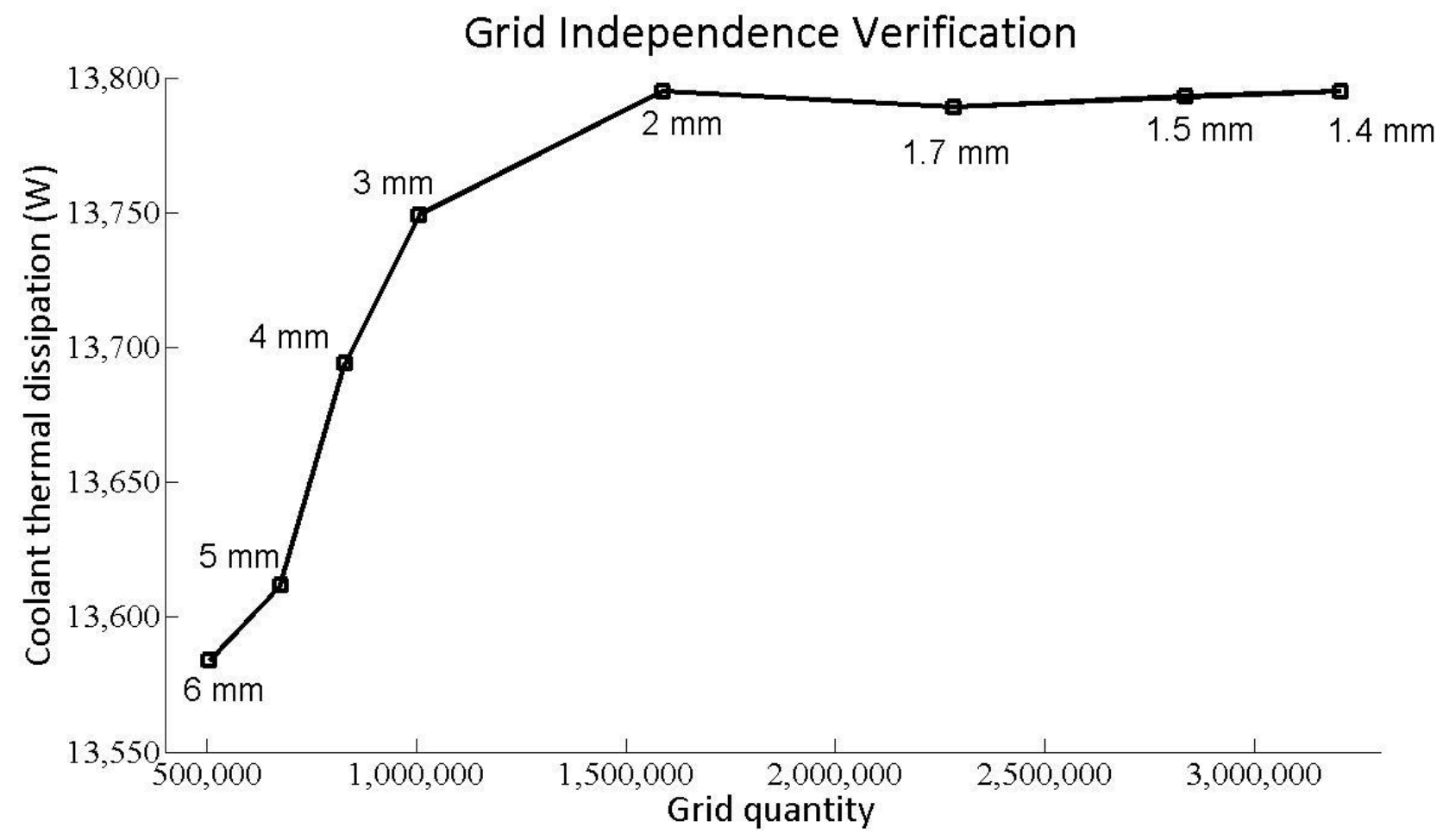

Fig.6. grid independence verification for the single cylinder model

In order to reduce the software solving time and maintain the accuracy of the simulation model, the grid independence analysis was conducted in this study. The mesh of the single cylinder model was generated with eight different sizes. The quantities of the grid size $6 \mathrm{~mm}, 5 \mathrm{~mm}, 4 \mathrm{~mm}, 3 \mathrm{~mm}, 2 \mathrm{~mm}, 1.7 \mathrm{~mm}, 1.5 \mathrm{~mm}$ and $1.4 \mathrm{~mm}$ is $506904,677289,830183,1007301,1587617,2283083,2836516$ and 3206417 , respectively. The coolant thermal dissipation of the engine was compared with eight different grid sizes and the results were plotted in Figure 6 . The grid independence analysis indicated that the optimal grid size in this study is $2 \mathrm{~mm}$, which can effectively be used in the 3D simulation model with similar accuracy of smaller size grid and saving the software solving time. 


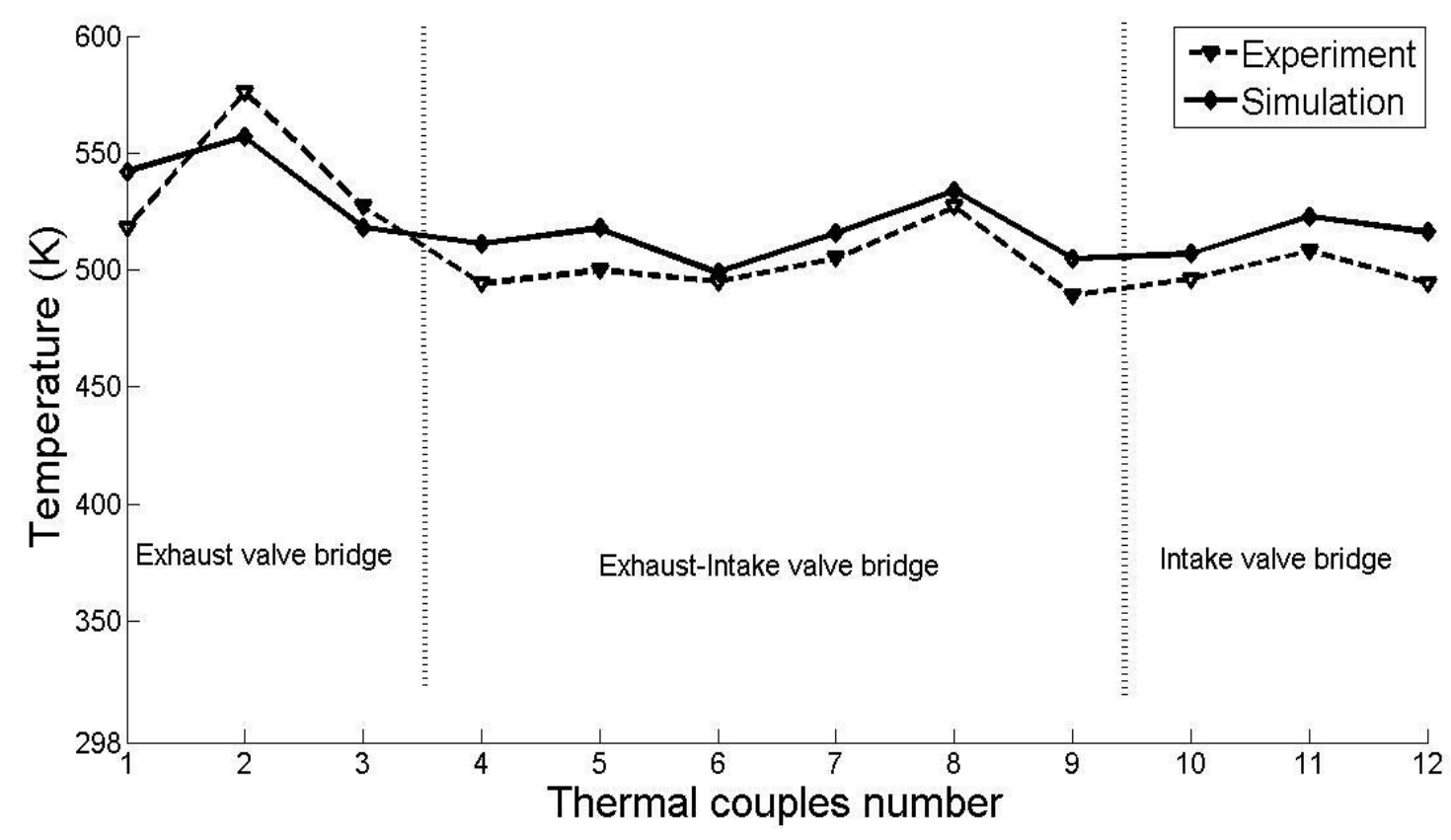

Fig.7 Simulation and experimental temperature data comparison

The simulation results were verified by the experimental data of a six-cylinder Internal Combustion Engine, which is obtained from authors' previous research work conducted in Department of Energy Engineering, Zhejiang University [26]. The temperature on the cylinder head fire face obtained from the 3D simulation model are compared with the experimental results, which shows good agreement between the simulation and experimental data as illustrated in Figure 7. 


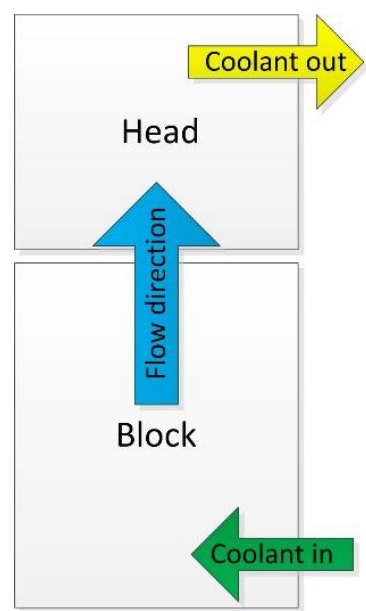

Case A

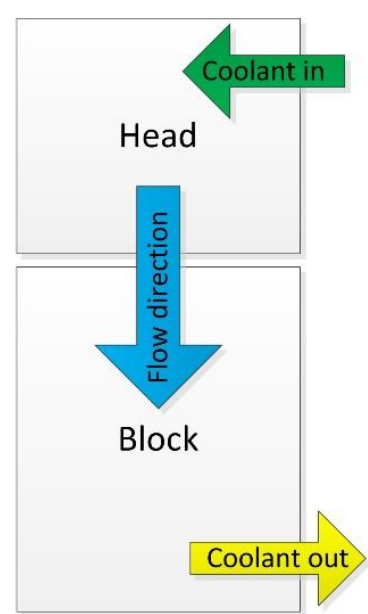

Case B

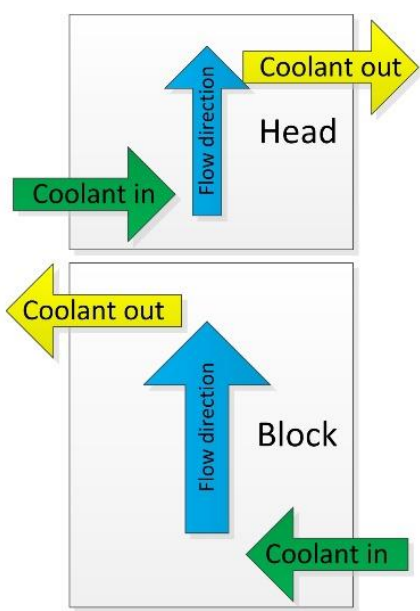

Case C

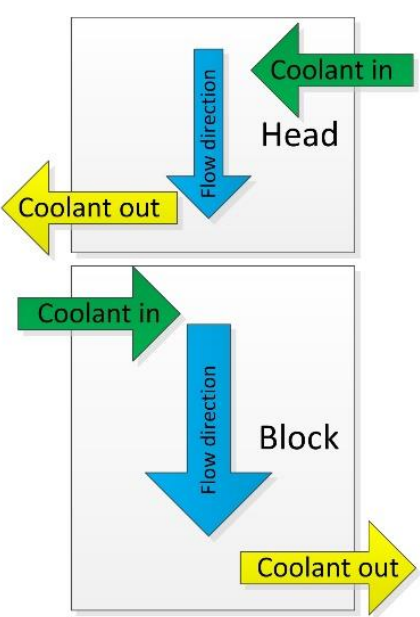

Case D

Fig.8 Schematic diagram of different cooling structures

Four different cooling structures are investigated and compared in this study. Case A represents the conventional cooling structure. The top-bottom flow cooling organization arranged the inlet of the coolant on the cylinder head and the outlet of the coolant on the block so that the flow direction of the coolant can be top to bottom as illustrated in Figure 8 Case B. The split cooling structure requires two separate cooling galleries for the cylinder head and block with independent coolant pumps and control units. Case $C$ and Case D in Figure 8 show the bottom-top and top-bottom split cooling structures. The simulation model was used to investigate the effect of the previously introduced four cooling structures on the thermal conditions of the heated component and thermal/frictional power dissipation of the cooling gallery. 


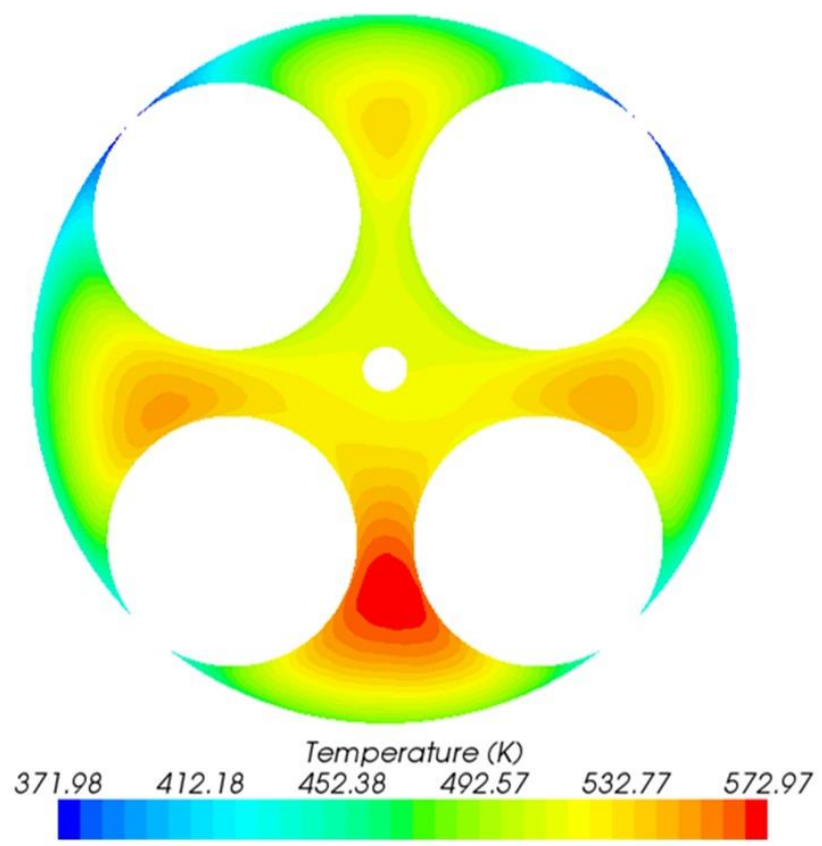

Case A

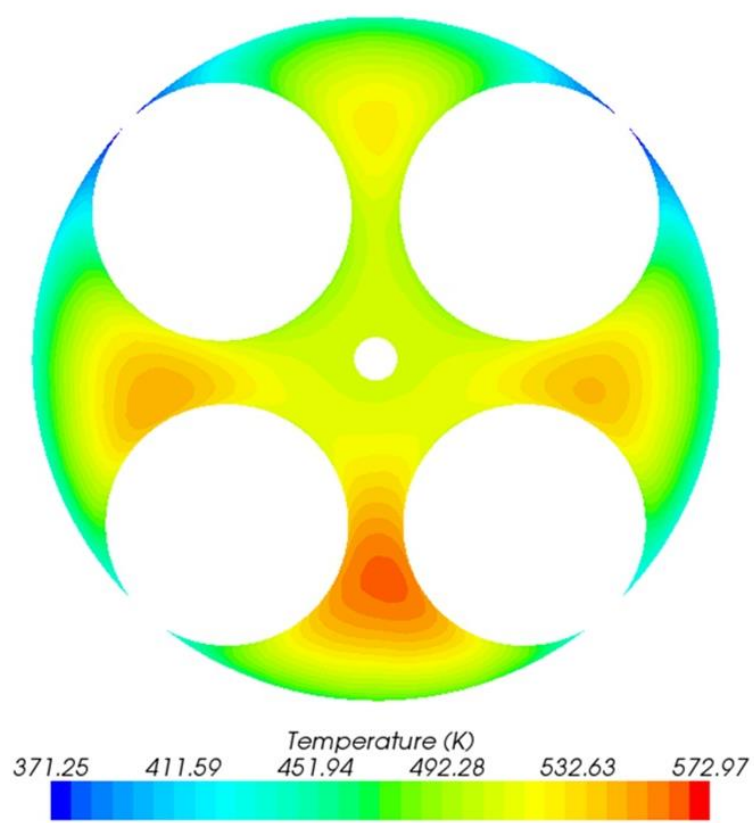

Case B

(a) Temperature field on the cylinder head fire face

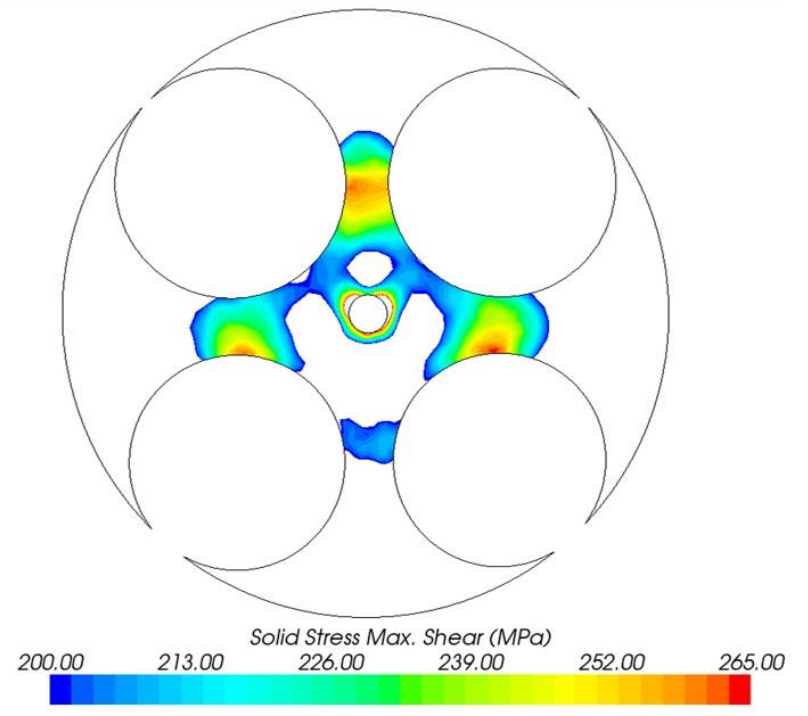

Case $\mathrm{A}$

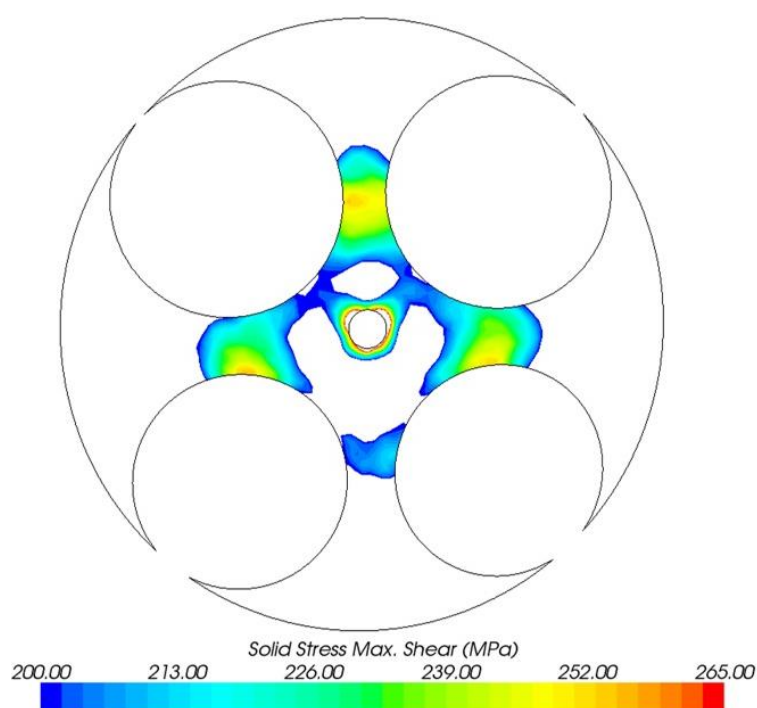

Case B

(b) thermal stress field on the cylinder head fire face

Fig. 9. Effect of the coolant flow direction on the head fire face thermal condition 
and analysed. The results obtained from the 3D engine simulation model are shown in Figure 9, which includes the temperature field and thermal stress field on the cylinder heat fire face of Case A and Case B. As indicated in Figure 9

(a), when the coolant flow direction changes from bottom-top (Case A) to top-bottom (Case B), the temperature

field of the cylinder head can be reduced. The temperature field of cylinder head and liner between Case A and Case

B are obtained from the 3D engine simulation model and summarised in Table 3. Results indicated the highest

temperature decrease can be as high as $9.49 \mathrm{~K}$ at the fire face of the cylinder head with the corresponding thermal

stress decreases from 321.18 MPa to $311.26 \mathrm{MPa}$. By using top-bottom cooling structure the maximum temperature of the fire face of the cylinder liner is increased by $1.59 \mathrm{~K}$, which is within the operational temperature range of the

Table 3

Comparison of the temperature field of cylinder head and liner between Case A and Case B

\begin{tabular}{|c|c|c|c|}
\hline & Case A & Case B & Change \\
\hline $\begin{array}{l}\text { Mean temperature of the water jacket wall of the } \\
\text { cylinder head }\end{array}$ & 356.84 & 355.58 & Decreased by $1.26 \mathrm{~K}$ \\
\hline Mean temperature of the cylinder head & 371.76 & 370.08 & Decreased by $1.68 \mathrm{~K}$ \\
\hline Mean temperature on the fire face of the cylinder head & 508.25 & 502.44 & Decreased by $5.81 \mathrm{~K}$ \\
\hline Max temperature on the fire face of the cylinder head & 572.97 & 563.48 & Decreased by $9.49 \mathrm{~K}$ \\
\hline Mean temperature of the water jacket wall for the liner & 351.30 & 356.43 & Increased by $5.13 \mathrm{~K}$ \\
\hline Mean temperature of the liner & 364.38 & 370.60 & Increased by $6.22 \mathrm{~K}$ \\
\hline Mean temperature on the fire face of the liner & 363.16 & 369.48 & Increased by $6.32 \mathrm{~K}$ \\
\hline Max temperature on the fire face of the liner & 494.93 & 496.52 & Increased by $1.59 \mathrm{~K}$ \\
\hline
\end{tabular}




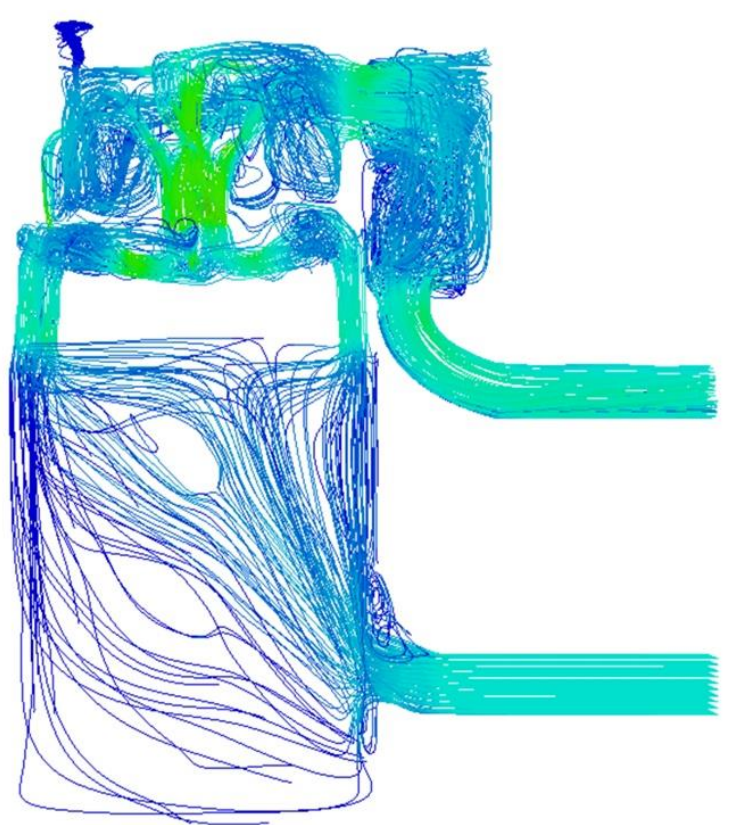

Velocity: Magnitude (m/s)

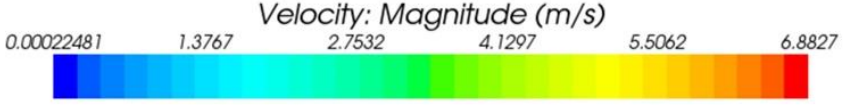

Case A
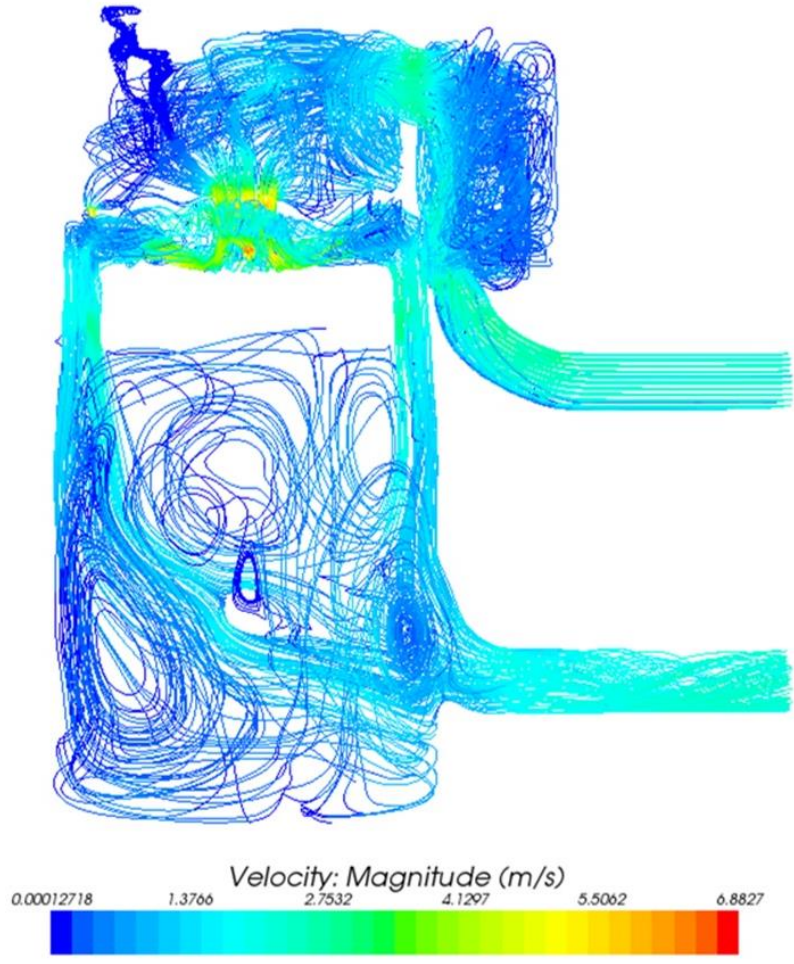

Case B

(a) Coolant velocity stream line contours
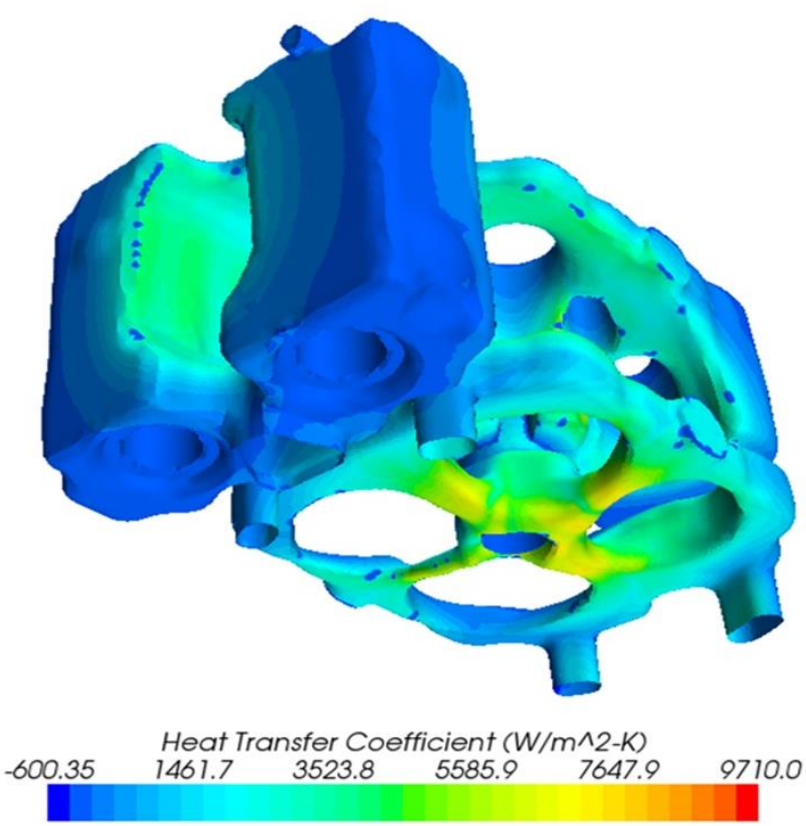

Case $\mathrm{A}$

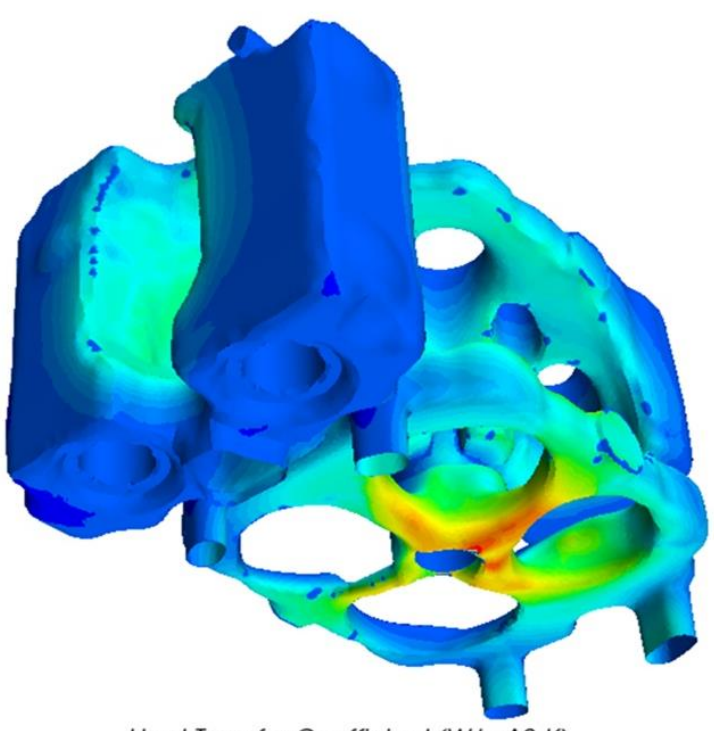

Heat Transfer Coefficient $\left(W / m^{\wedge} 2-K\right)$

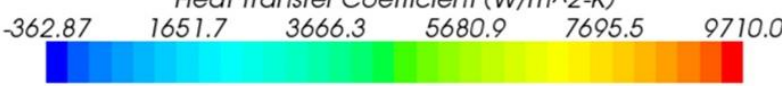

Case B

(b) Cylinder head coolant side HTC contours

Fig. 10 Effect of the flow direction on the coolant condition and HTC 
maximum coolant flow speed was observed in the cooling gallery of the oil injector as indicated in Figure 10 (a) with the velocity at $5.83 \mathrm{~m} / \mathrm{s}$ in Case A and $6.88 \mathrm{~m} / \mathrm{s}$ in Case B. The results also indicated that coolant flow speed can be effectively improved at the location of the valve bridge of the cylinder head fire face when the top-bottom cooling structure (Case B) was used to replace the conventional cooling structure (Case A). The HTC analysis suggested the overall HTC value can be effectively improved by adopting top-bottom cooling structure (Case B) to replace

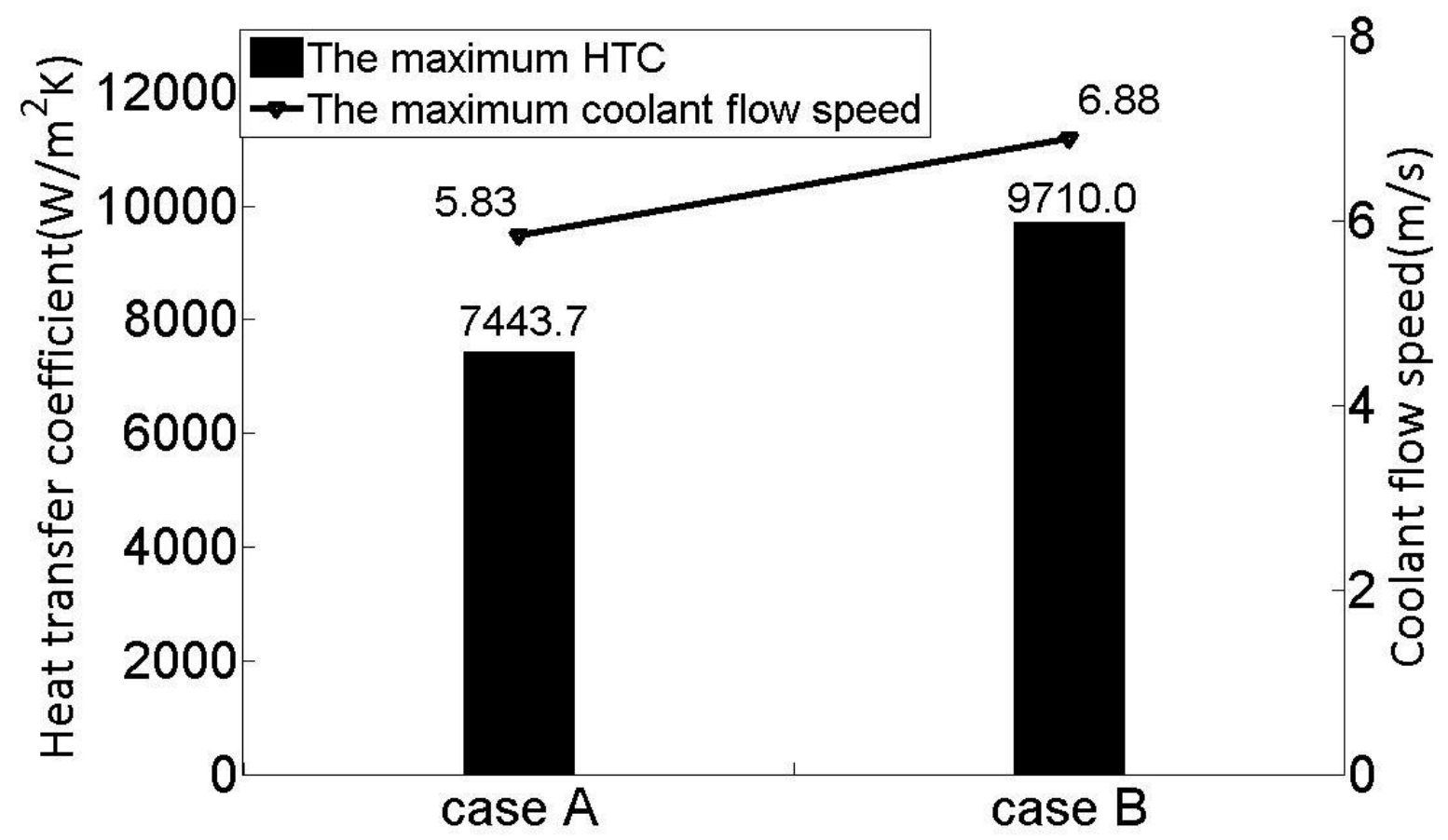

Fig. 11. Coolant flow speed and HTC comparison between case A and case B

In summary, the flow distribution analysis of the cooling gallery of the cylinder head indicated that the top-bottom cooling structure can effectively force the coolant scour the bottom surface of the cooling gallery to the valve bridge 

and reduced coolant temperature in Case B lead to the reduction of the temperature field of the cylinder head fire face and the reduction of temperature gradient/thermal stress.

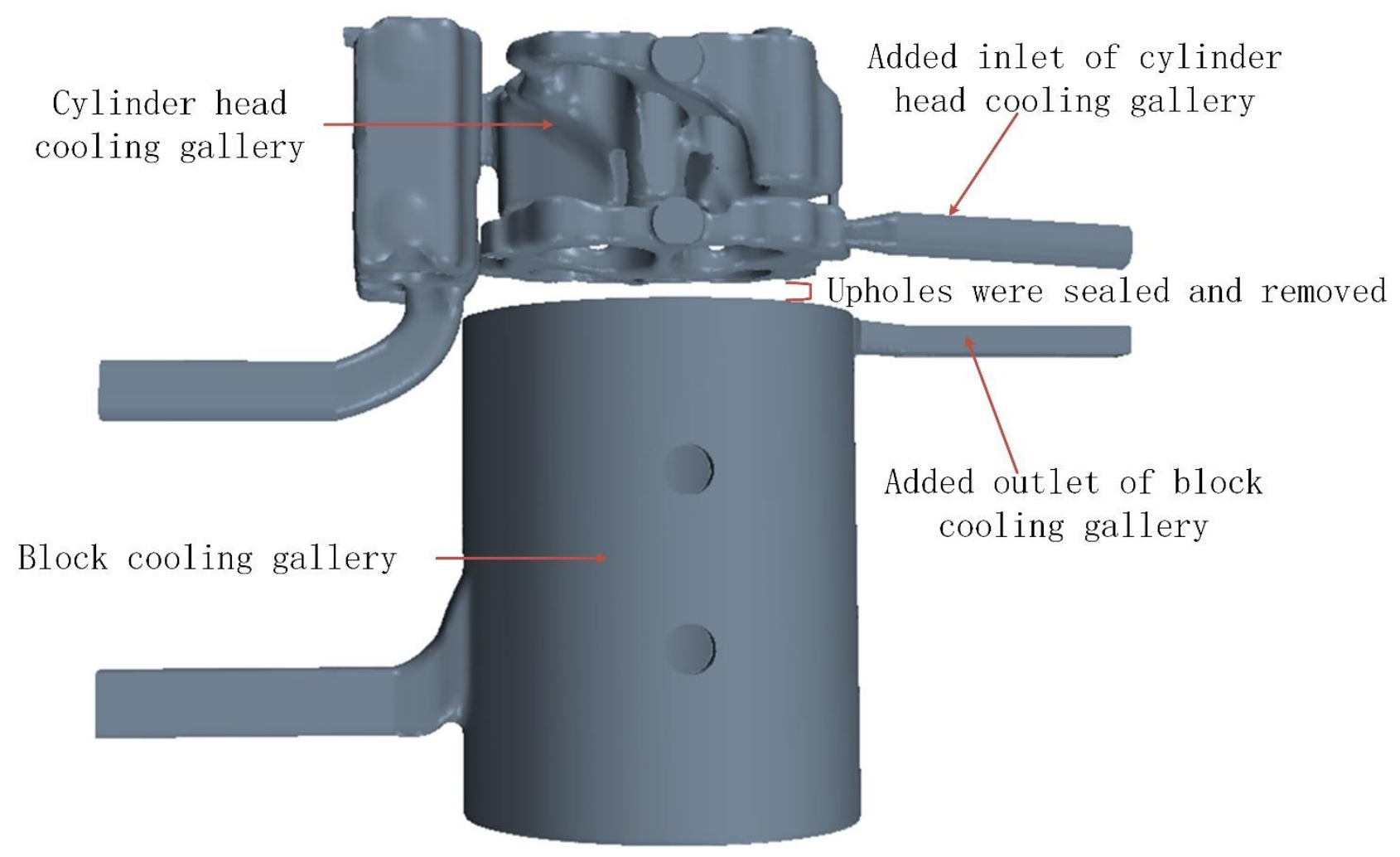

Fig 12. Split cooling gallery structure

The split cooling structure has several modifications on the original cooling system, including seal the upper holes, 
Engine, various coolant flux distributions of the two separately coolant circuits of cylinder head and block were studied. The flux proportion $\alpha$ was defined as the coolant flux of cylinder head $Q_{H}$ divided by the total coolant flux

$Q_{T}$ with the range from 0.1 to 0.9 as illustrated in Equation (15).

$$
\alpha=\frac{Q_{H}}{Q_{T}}
$$

The total coolant flux $Q_{T}$ is set at $1.1 \mathrm{~kg} / \mathrm{s}$, which is the same as that in Case A. The comparison of the average and maximum temperature at the cylinder head and liner fire face of four different cooling structures under different

202 split coolant flux can be found in Figure 13.
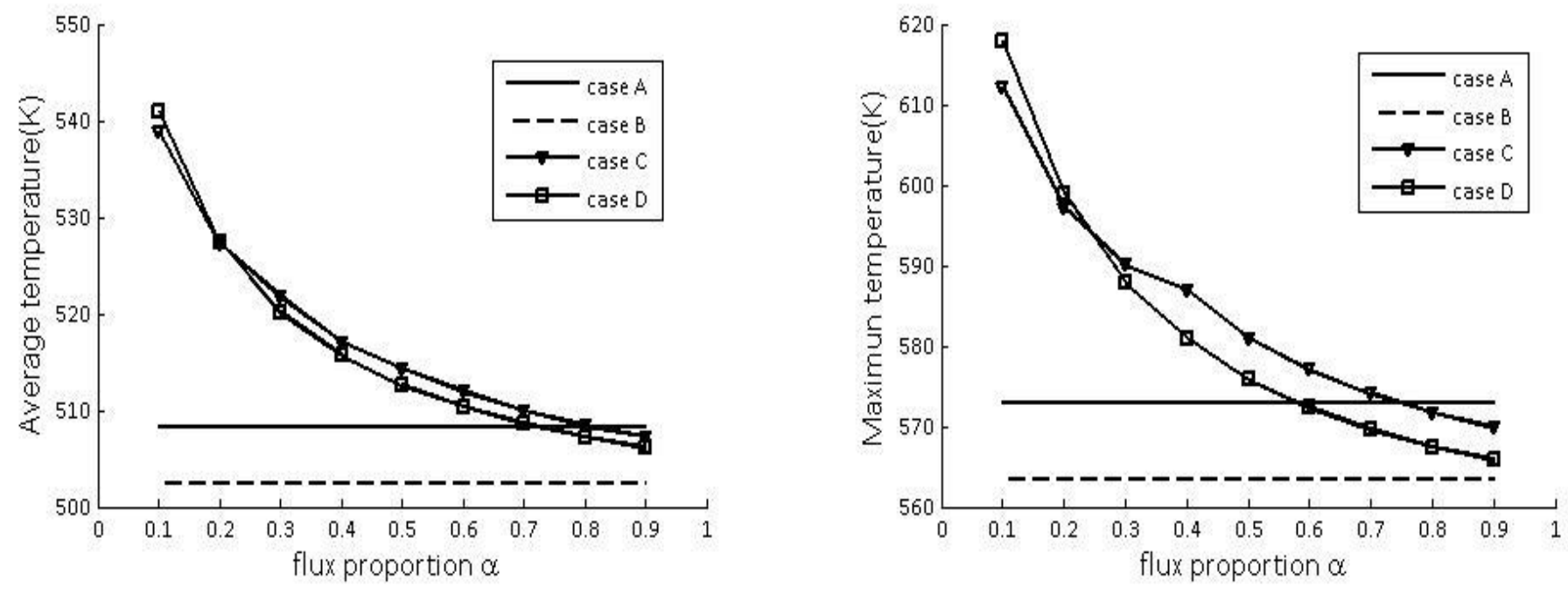

(a) Average and maximum temperature of the cylinder head fire face 

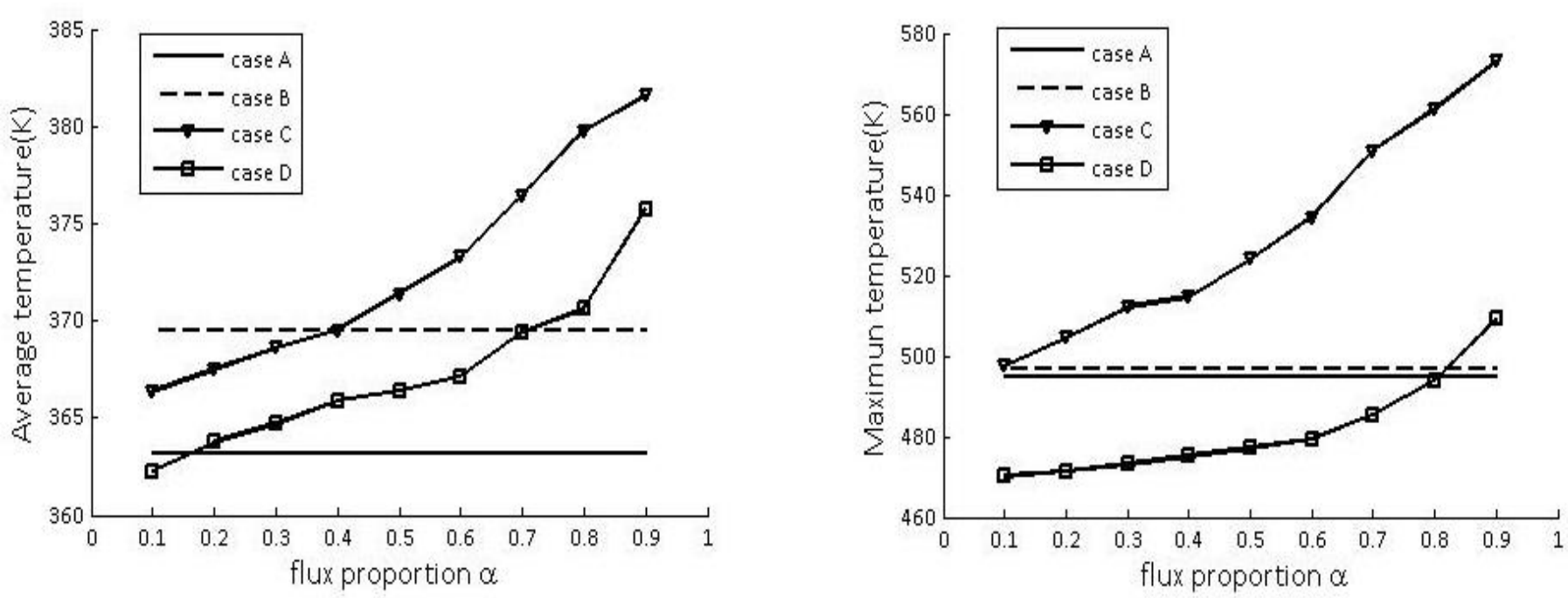

(b) Average and maximum temperature of the liner fire face

Fig. 13. The head and liner fire face temperature variation

As indicated in Figure 13 (a), the temperature field on the cylinder head decreases with the increase of flux

proportion $\alpha$ in split cooling structures (Case $\mathrm{C}$ and Case $\mathrm{D}$ ). When the flux proportion is higher than 0.8 , the average and maximum temperatures on the cylinder head fire-face in Case $C$ is lower than that of Case $A$, and the temperature field on the liner fire face is higher than that of Case A. However, the maximum temperature of the liner fire face can be as high as $561.16 \mathrm{~K}$, which is much higher than the conventional operation temperature of the liner material, when the flux proportion is set at 0.8 . Therefore, the Case $\mathrm{C}$ cooling structure is not recommended as an alternative cooling structure to avoid the damage of cylinder liner.

When the flux proportion is higher than 0.7 , the average and maximum temperature on the cylinder head fire-face in case $D$ is lower than that of case $A$. And the maximum temperature of liner fire face is slightly higher than that of case $A$ when the flux proportion is higher than 0.8 , while the temperature is still in the operational temperature range of the cylinder liner material. In conclusion, the results achieved in Figure 13 indicated that the optimal coolant flux proportion can be higher than 0.8 in case $D$, which can effectively achieve lower cylinder head 
As mentioned above, an important portion of the combustion energy is dissipated from the coolant. In addition, power is consumed by coolant pump to overcome frictional resistance and used by cooling fan to dump the heat energy into the environment[27]. The reduced requirement of thermal dissipation from the coolant and the reduced friction power dissipation of the coolant fluid can save the power consumed by the coolant pump and cooling fan, respectively.

As discussed previously, Case $C$ is not recommended to be used because of the maximum temperature of the liner 226 fire face is too high, which will increase the potential of damaging the cylinder liner material. Case A, Case B and 227 Case $D$ are therefore selected to evaluate the thermal and friction power dissipation. The coolant flux proportion of case $D$ is set at 0.9, which is within the optimal operational region as illustrated in Figure 13. following equations.

$$
\begin{gathered}
P_{c}=\sum_{j=H, \mathrm{~B}} Q_{j} \bullet \Delta T_{j} \\
P_{f}=\sum_{j=H, \mathrm{~B}} Q_{v_{j}} \bullet \Delta p_{j}
\end{gathered}
$$



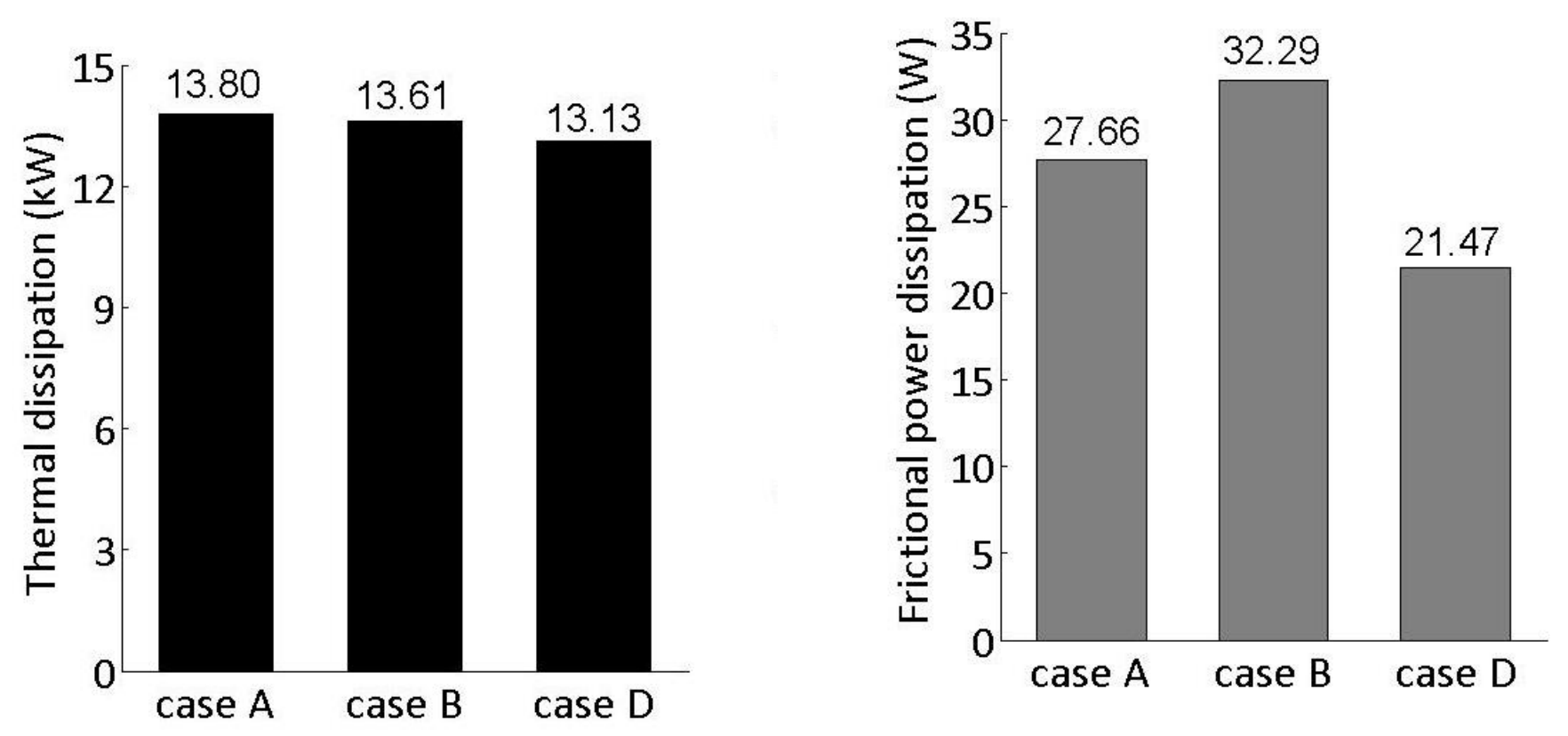

Fig. 14. Thermal and frictional power dissipation comparison

The comparison of the thermal and friction power dissipation for Case A, Case B and Case D under the coolant flux

proportion at 0.9 is drawn in Figure 14. The cooling gallery thermal dissipation of Case $A$ is $13.80 \mathrm{~kW}$, while those of

case B and case D are $13.61 \mathrm{~kW}$ and $13.13 \mathrm{~kW}$, respectively. The power dissipation of Case A, Case B and Case D are

$27.66 \mathrm{~W}, 32.29 \mathrm{~W}$ and $21.47 \mathrm{~W}$, respectively.

The thermal dissipation of Case B is reduced by $1.37 \%$ and that of Case $D$ is reduced by $4.86 \%$ compared with that of

Case A. However, the requirement of overcoming the frictional power dissipation of Case B is increased by $16.74 \%$

compared with that of Case A, which means the top bottom cooling structure (Case B) requires higher pump power.

The friction power dissipation of Case D can be reduced by $22.38 \%$ compared with that of Case A. Both the thermal dissipation from the coolant and the friction power dissipation of the coolant can be effectively reduced when Case

D is used as an alternative cooling structure for the Internal Combustion Engine.

As mentioned above, in the top-bottom cooling structure (Case B), the liner temperature can increase because of the 
247 further increased by reduction the flux of the liner cooling circuit, which means the thermal power dissipation, can

248 be less than that of Case B and Case A. By adopting the Case D cooling structure, not only the coolant fluxes for the 249 cylinder head or the block can be reduced but also frictional power dissipation of the coolant can be reduced.

250 In conclusion, Case D integrates the top-bottom cooling and split structure cooling structures with the advantage of relatively lower coolant temperature and higher heat transfer coefficient for the cylinder head fire-face and controllable flux proportion for both coolant circuits. The Case D is the optimal scheme within the four types of cooling structure with the benefits of low thermal loss, low friction power dissipation and optimal temperature field 254 of the cylinder head and liner.

\subsection{Coolant Distribution of the Optimal Scheme}

In order to calculate the appropriate flux distribution in the optimal scheme at different combustion intensities and compare the cooling performance of the original and optimal organizations, the engine power output was increased by $5 \%, 10 \%$ and $15 \%$ to evaluate the difference. As shown in Figure 15 , the maximum temperature of the cylinder head and liner fire-face increases with increasing output power, and the maximum temperature difference between the cylinder head and liner continues to increase as well, which means the thermal non-uniformity is intensified. 


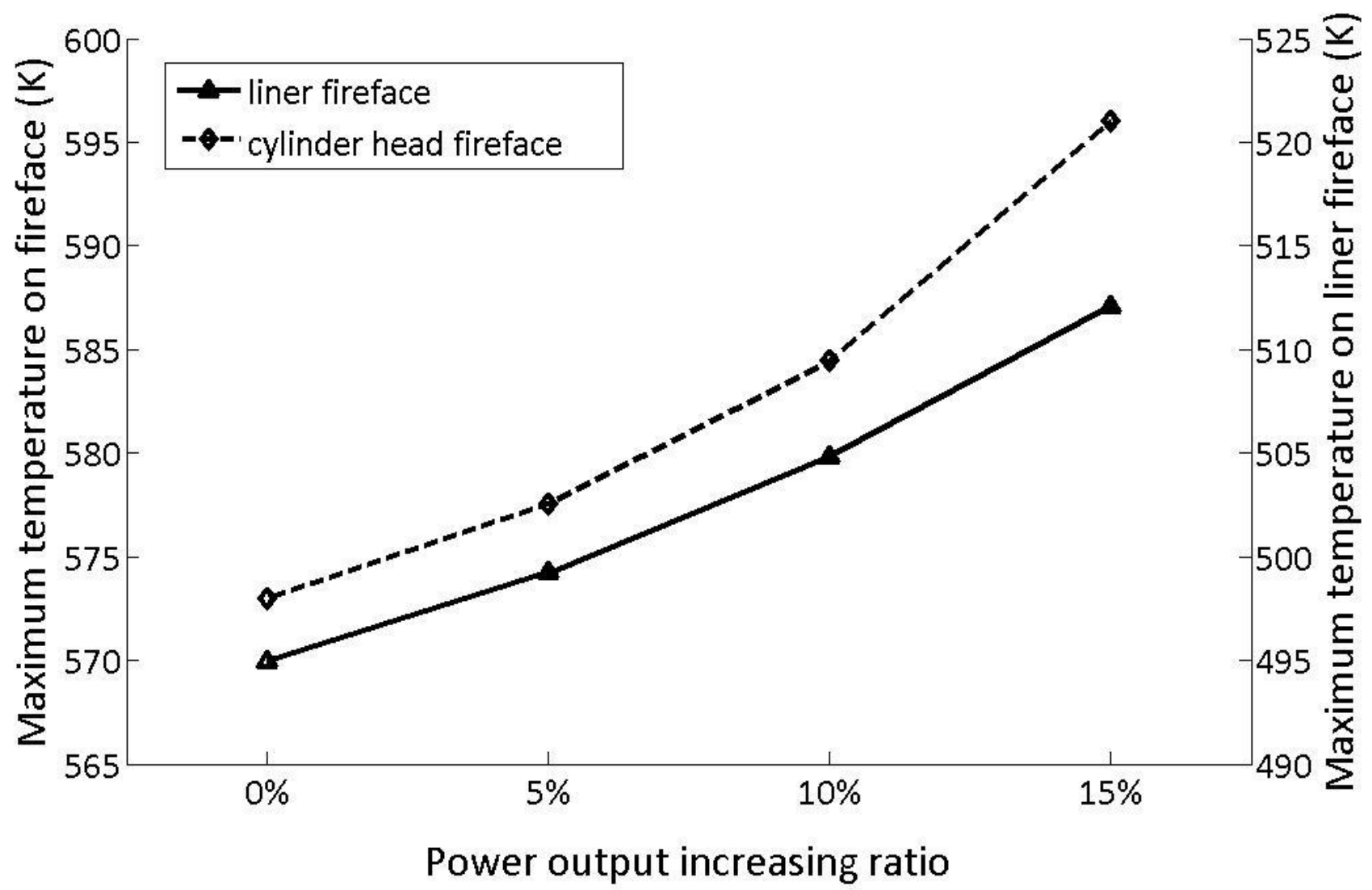

Fig. 15. Maximum temperature on the fire-face with increasing power output

264 For the sake of adapting the increased power output, the coolant flux in the original cooling scheme (Case A) was

265 increased to satisfy the cooling need of the cylinder head. The maximum temperature on the cylinder head fire face

266 is set at $572.97 \mathrm{~K}$ as the benchmark. In the optimal scheme (Case $\mathrm{D}$ ), the total coolant flux $Q_{T}$ and the flux

267 proportion $\alpha$ are controlled to maintain the maximum temperatures on the cylinder head and liner fire-face at 


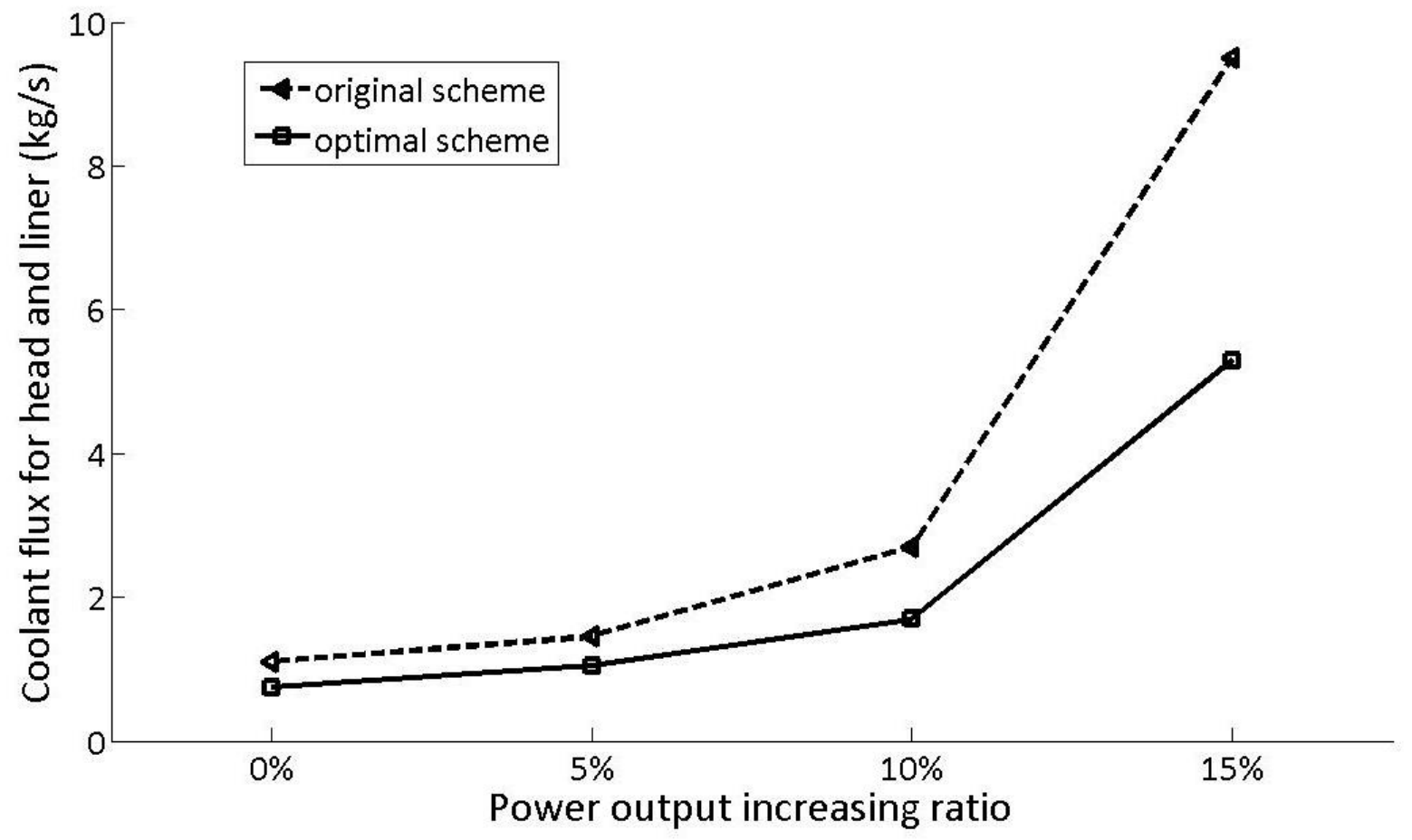

Fig. 16. Coolant flux variation with increasing power output

270 As illustrated in Figure 16, the relationship between the coolant flux and engine power output is not linearly related.

271 The detailed values of the flux with the engine power output increase are summarised in Table 4. In optimal scheme

272 (Case D), the flux proportion $\alpha$ is also increased with the change of engine power output, which is caused by the

273 increased temperature difference between the temperature of cylinder head and liner fir face.

\section{Cooling parameters of the original and optimal schemes with increasing power output}

\begin{tabular}{cccc}
\hline $\begin{array}{c}\text { Power output increasing } \\
\text { ratio }\end{array}$ & $\begin{array}{c}\text { Coolant flux of the original } \\
\text { scheme }(\mathrm{kg} / \mathrm{s})\end{array}$ & Total coolant flux $(\mathrm{kg} / \mathrm{s})$ & Flux proportion $\alpha$ \\
\hline $0 \%$ & 1.1 & 0.75 & 0.85 \\
$5 \%$ & 1.45 & 1.05 & 0.88 \\
$10 \%$ & 2.7 & 1.7 & 0.91
\end{tabular}


The optimal scheme can effectively reduce the coolant flux by $0.35 \mathrm{~kg} / \mathrm{s}, 0.4 \mathrm{~kg} / \mathrm{s}, 1 \mathrm{~kg} / \mathrm{s}$ and $4.2 \mathrm{~kg} / \mathrm{s}$ under different engine power output as listed in Table 4, which will also leads the reduction of frictional power dissipation consumed

279 by the coolant pump. The changes of friction power dissipation can then be calculated by Equation (16). The

280 calculated results indicated that the friction power dissipation $P_{f}$ can be reduced by as high as $36.41 \%, 41.14 \%$,

$28157.80 \%$ and $65.95 \%$ under the four selected engine power output conditions compared with that of the original

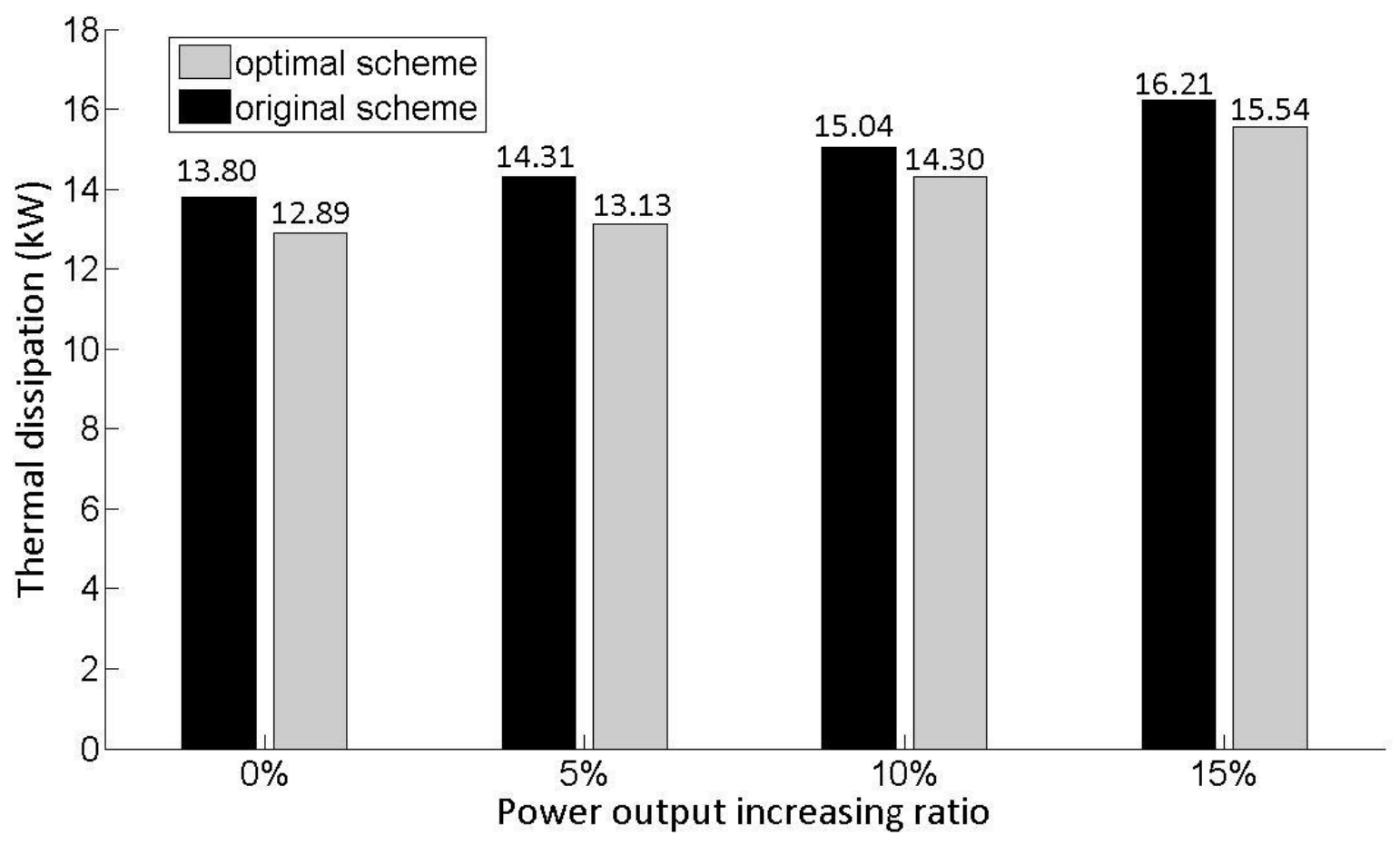

Fig. 17. Thermal dissipation under different engine power output increasing ratio 


\section{Conclusions}

In this study, the effects of four different cooling structures for Internal Combustion Engine were reported. A 3D

single cylinder engine simulation model was built in the software Starccm + in order to predict the temperature

status of the Internal Combustion Engine under different cooling structures. The conclusions drawn from this study can be summarised as

1. The analysis and comparison between bottom-top cooling structure (Case A) and top-bottom cooling structure indicate that the Case B can effectively cool down the cylinder head and maintain the temperature of cylinder head lower than that of the cylinder liner, which meets the cooling intensity need for the head and liner. By using the top-bottom cooling structure, the coolant can scour the bottom surface of the cooling gallery close to the valve bridge. The mean temperature of the cylinder head can be reduced by $1.68 \mathrm{~K}$ and the mean temperature on the fire face of the cylinder head can be decreased by $5.81 \mathrm{~K}$ at the engine rated condition, which can potentially reduce the thermal stress of the engine cylinder head to extend the component life time. Moreover, the maximum heat transfer coefficient obtained at the cylinder head is improved from $7443.7 \mathrm{~W} / \mathrm{m} 2 \mathrm{~K}$ in Case $A$ and $9710.0 \mathrm{~W} / \mathrm{m} 2 \mathrm{~K}$ in Case $B$.

2. The split cooling structure can separately control the flux of the cylinder head and block to meet various cooling requirements. The bottom-top split cooling structure (Case C) is not recommended to be used because this type of cooling structure will lead to too high temperature at cylinder liner fire face, which is not preferred for the application in Internal Combustion Engine. The top-bottom split cooling structure (Case D) is identified as the optimal solution with the advantages of better thermal condition of the cylinder head and liner, $4.86 \%$ lower thermal dissipation from the coolant and $22.38 \%$ lower frictional dissipation, which means the power consumed by the cooling pump and fan can be effectively reduced.

3. The evaluation of coolant distribution of the optimal scheme (Case D) under different engine power output increasing ratio $(0 \%, 5 \%, 10 \%$ and $15 \%)$ indicates the flux proportion $\alpha$ increases with the increase of power 
and $4.13 \%$, respectively.

\section{Acknowledgments}

The authors would like to thank the support from Weichai Power Co., Ltd under the project: Cooling Uniformity Design of Power Density Diesel Engine to conduct this study and the support from NSFC-RS Joint Project under the grant number No. 5151101443 and IE/151256.

\section{References}

[1] R. Saidur, M. Rezaei, W.K. Muzammil, M.H. Hassan, S. Paria, M. Hasanuzzaman, Technologies to recover exhaust heat from internal combustion engines, Renewable and Sustainable Energy Reviews, 16 (2012) 5649-5659.

[2] E.H. Wang, H.G. Zhang, Y. Zhao, B.Y. Fan, Y.T. Wu, Q.H. Mu, Performance analysis of a novel system combining a dual loop organic Rankine cycle (ORC) with a gasoline engine, Energy, 43 (2012) 385-395.

[3] S. Song, H. Zhang, Z. Lou, F. Yang, K. Yang, H. Wang, C. Bei, Y. Chang, B. Yao, Performance analysis of exhaust waste heat recovery system for stationary CNG engine based on organic Rankine cycle, Applied Thermal Engineering, 76 (2015) 301-309.

[4] Y. Lu, Y. Wang, C. Dong, L. Wang, A.P. Roskilly, Design and assessment on a novel integrated system for power and refrigeration using waste heat from diesel engine, Applied Thermal Engineering, 91 (2015) 591-599.

[5] J.B. Heywood, Internal Combustion Engine Fundamentals, McGraw-Hill, 1988.

[6] F. Zieher*, F. Langmayr, A. Jelatancev, K. Wieser, Thermal Mechanical Fatigue Simulation of Cast iron Cylinder Heads, in, SAE International, 2005.

[7] S. Fontanesi, M. Giacopini, Multiphase CFD-CHT optimization of the cooling jacket and FEM analysis of the engine head of a V6 diesel engine, Applied Thermal Engineering, 52 (2013) 293-303.

[8] F. Pizzonia, T. Castiglione, S. Bova, A Robust Model Predictive Control for efficient thermal management of internal combustion engines, Applied Energy, 169 (2016) 555-566.

[9] J.F. Eberth, J.R. Wagner, B.A. Afshar, R.C. Foster, Modeling and Validation of Automotive "Smart" Thermal Management System Architectures, in, SAE International, 2004.

[10] F. Caresana, M. Bilancia, C.M. Bartolini, Numerical method for assessing the potential of smart engine thermal management: Application to a medium-upper segment passenger car, Applied Thermal Engineering, 31 (2011) 3559-3568.

[11] E.S. Mohamed, Experimental study on the effect of active engine thermal management on a bi-fuel engine performance, combustion and exhaust emissions, Applied Thermal Engineering, 106 (2016) 1352-1365.

[12] D.J. Allen, M.P. Lasecki, Thermal Management Evolution and Controlled Coolant Flow, in, SAE International, 2001.

[13] Y.H. Shin, S.C. Kim, M.S. Kim, Use of electromagnetic clutch water pumps in vehicle engine cooling systems to reduce fuel consumption, Energy, 57 (2013) 624-631.

[14] E.S. Mohamed, Development and analysis of a variable position thermostat for smart cooling system of a light duty diesel vehicles and engine emissions assessment during NEDC, Applied Thermal Engineering, 99 (2016) 358-372. [15] R. Cipollone, D. Di Battista, A. Gualtieri, A novel engine cooling system with two circuits operating at different temperatures, Energy Conversion and Management, 75 (2013) 581-592. 
[16] C. Malvicino, F. Di Sciullo, W. Ferraris, F. Vestrelli, F. Beltramelli, Advanced Dual Level Vehicle Heat Rejection System for Passenger Cars, (2012).

[17] H. Kang, H. Ahn, K. Min, Smart cooling system of the double loop coolant structure with engine thermal management modeling, Applied Thermal Engineering, 79 (2015) 124-131.

[18] R. Cipollone, D. Di Battista, A. Gualtieri, Head and block split cooling in ICE, IFAC Proceedings Volumes, 45 (2012) 400-407.

[19] R. Ernst, R. Friedfeldt, S. Lamb, D. Lloyd-Thomas, P. Phlips, R. Russell, T. Zenner, The New 3 Cylinder 1.0L Gasoline Direct Injection Turbo Engine from Ford, in: In 20th Aachen Colloquium Automobile and Engine Technology, 2011.

[20] Wikipedia, Computational Dynamics-Analysis \& Design Application Company Ltd https://en.wikipedia.org/wiki/CD-adapco, in, Achieved on 26th Oct 2016.

[21] J.M. Wu, W.Q. Tao, Numerical study on laminar convection heat transfer in a rectangular channel with longitudinal vortex generator. Part A: Verification of field synergy principle, International Journal of Heat and Mass Transfer, 51 (2008) 1179-1191.

[22] J. Bayat, A.H. Nikseresht, Thermal performance and pressure drop analysis of nanofluids in turbulent forced convective flows, International Journal of Thermal Sciences, 60 (2012) 236-243.

[23] W.-C. Chen, W.-T. Cheng, Numerical simulation on forced convective heat transfer of titanium dioxide/water nanofluid in the cooling stave of blast furnace, International Communications in Heat and Mass Transfer, 71 (2016) 208-215.

[24] A. BOOST ${ }^{\mathrm{TM}}$, https://www.avl.com/boost, in, Achieved on 26th Oct 2016.

[25] Y. Zhang, Fundamental Research on Conjugate Heat Transfer Modeling for High Power Density Diesel Engine Simulation, in: Department of Energy Engineering, Vol. Ph. D, Zhejiang University, 2013, pp. 155.

[26] X. Yin, Fundamental Reaserch on Thermal Reliability Engineering Design for Cylinder Head in: Department of Energy Engineering, Vol. Ph. D., Zhejiang University, 2015, pp. 162.

[27] K. Zhu, G.-Q. Xu, Z. Tao, H.-W. Deng, Z.-H. Ran, C.-B. Zhang, Flow frictional resistance characteristics of kerosene RP-3 in horizontal circular tube at supercritical pressure, Experimental Thermal and Fluid Science, 44 (2013) 245-252. 